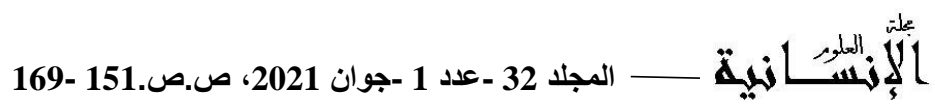

\title{
مقاربة الاتحاد الأوروبي في تدبير الأزمة في الساحل الأفريقي.
}

\author{
The European Union's Approach to manage the crisis in the Sahel \\ تاريخ الاستلام: 2020/02/12؛ تاريخ القبول: 2021/02/15
}

\begin{tabular}{|c|c|}
\hline & ملخص \\
\hline & 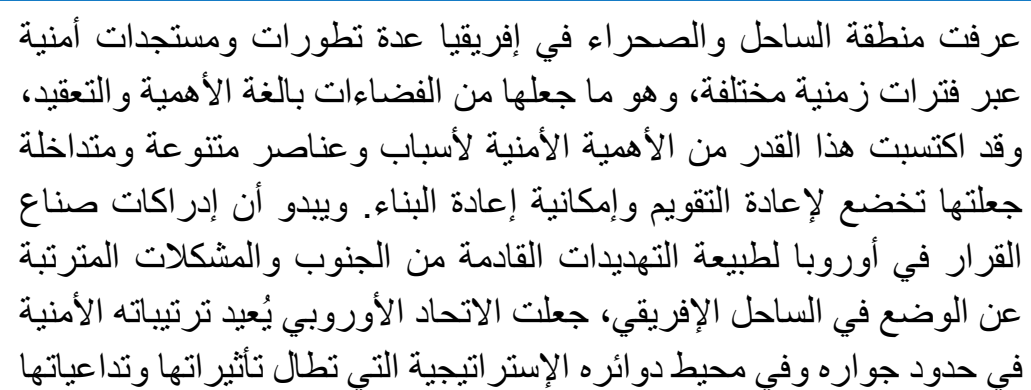 \\
\hline 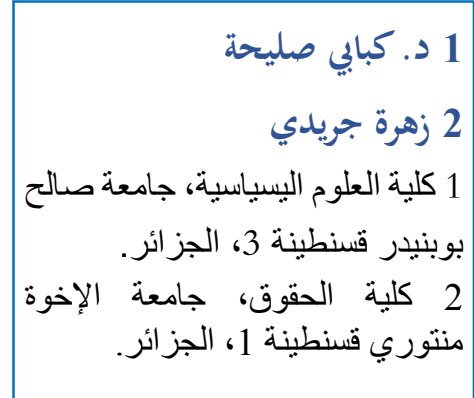 & 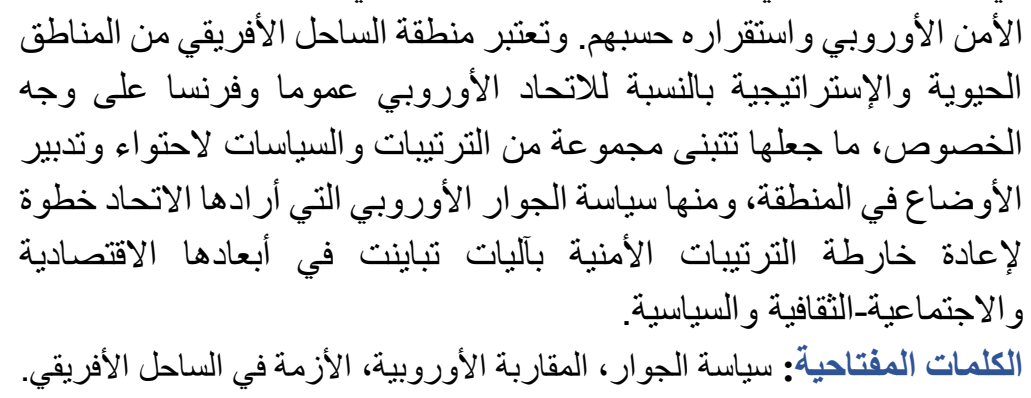 \\
\hline
\end{tabular}

\section{Abstract}

The Sahel region in Africa has been exposed to several developments and security updates across different time periods, making it as a very important and complex space with a high acquired degree of security importance; because of various and overlapping reasons and elements that have made it a subject for eventual reevaluation and possible rebuilding. However, it appears that the decision makers' perceptions in Europe about threats coming from the south and the problems posed by the situation on the Sahel- region, push the European Union to reorder its security arrangements within its Neighboring borders. These are the arrangements that have resulted in a set of policies which has been known as the European Neighborhood Policy that aims to contain security threats, with a new map of security arrangements with different dimensions: economic, social, cultural and political.

Keywords: neighborhood policy, European approach, Crisis on the African Coast.

\section{Résumé}

La région sahélo-saharienne en Afrique a connu plusieurs développements sécuritaires et ce durant des périodes différentes ; ce qui en a fait d'elle un espace extrêmement important et complexe, du a des raisons multiples et a des facteurs divers. Cependant, il semble que la perception des décideurs européens de la nature des menaces venant du sud et des problèmes liés à la situation sur la côte africaine ; a conduit l'Union européenne à rétablir ses dispositifs de sécurité dans son voisinage et à proximité de ses cercles stratégiques dont les impacts et les répercussions affectent -selon eux- la sécurité et la stabilité européennes.

La région du Sahel africain est considérée comme un espace vital et stratégique pour l'Union européenne en général et la France en particulier, ce qui l'a obligée à adopter un ensemble de dispositions et de politiques pour mieux gérer la crise dans la région, y compris la politique européenne de voisinage, dont l'Union voudrait que ce soit une étape pour repenser l'agenda européen de sécurité avec des mécanismes a plusieurs dimensions : économiques, socio-culturelles et politique.

Mots clés: UE, Sahel, politique de voisinage, sécurité.

* Corresponding author, e-mail: saliha.kebbabi@univ-constantine3.dz 
عرفت منطقة الساحل والصحراء في إفريقيا عدة تطورات ومستجدات عبر فترات

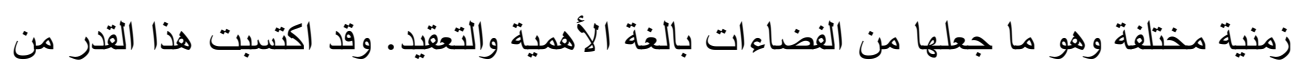
الأهية الأمنية لأسباب وعناصر متتوعة ومتداخلة جعلتها تخضع لإعادة التقويم وإمكانية

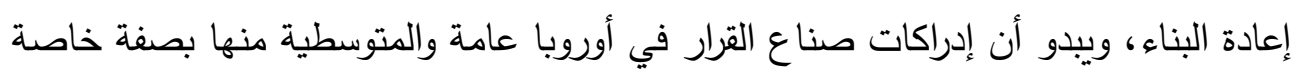

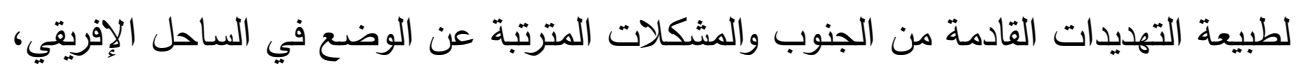
جعلت الاتحاد الأوروبي يعيد بناء ترتيباته الأمنية في حدود جواره وفي محيط دوائره

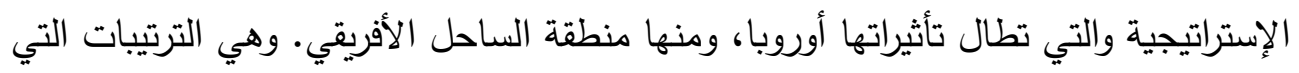

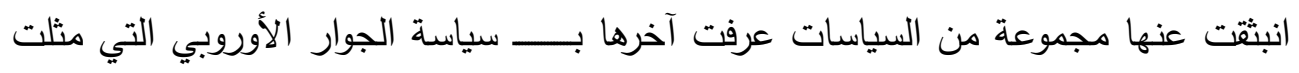

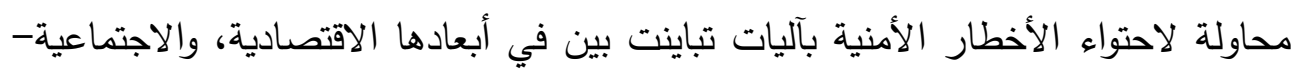
الثقافية والسياسية. ظهرت بعد انتهاء الحرب الباردة مجموعة من التهديدات الأمنية التي كان لها أثر في تدهور الوضع الأمني الدولي عموما، ومنطقة الساحل الأفريقي بصفة خاصة، ومنها: الإرهاب، والجريمة المنظمة العابرة للحدود والهجرة غير الشرعية، وتجارة الأسلحة والمخدرات، وتجارة البشر وغيرها من المخاطر التي تجاوزت حدود الدول وقدراتها في التعامل مع الأسباب والنتائج

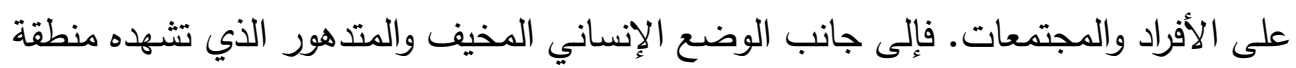
الساحل الأفريقي، تعددت التوترات والنزاعات الداخلية التي تعود في الأصل الإلى اللى طبيعة البيئة الاخلية للمنطقة وخصوصياتها: كالفشل السياسي وعدم تجانس التركيبة المجتمعية والتعددية

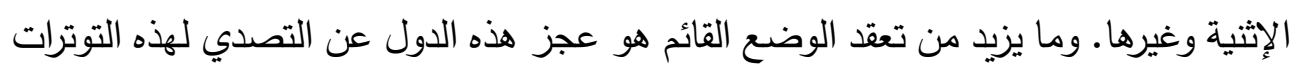

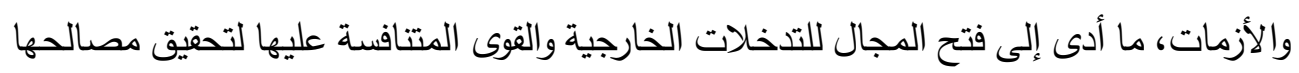

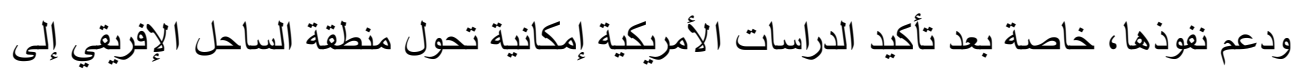

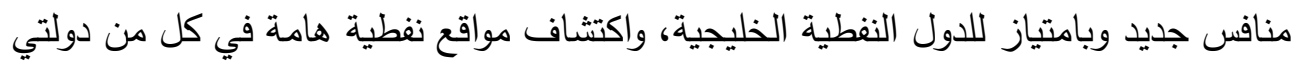
تشاد ومالي. الثيء الذي جعل الاتحاد الأوروبي يعمل جاهدا لوضع إستراتيجية من اجل التئل

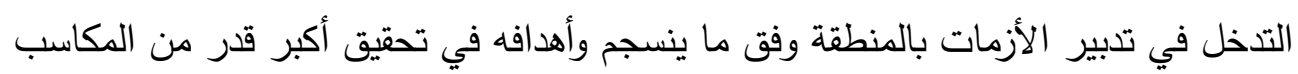

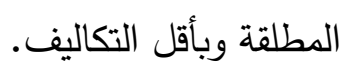

على هذا الأساس يمكن لنا التساؤل عن طبيعة وحجم الإسهامات التي خص بها الاتحاد

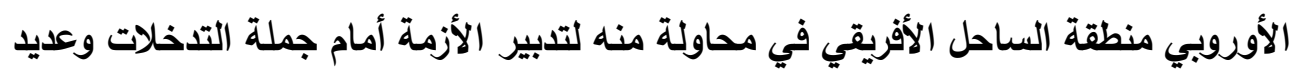
الفواعل الخارجية وتعقد إثكالية إعادة الاستقرار الأمني في المنطقة. يندرج تحت هذه الإشكالية سؤالان فرعيان: 
1_ ما هي خلفية التتخل الأوروبي في منطقة الساحل الأفريقي، سيما في ظل تعدد ترتيباته سياسيته الجوارية لاستغلال ثروات المنطقة ومزاياها؟ 2_ ما هو حجم التوافق بين منطلبات تحقيق هذه السياسة وبين خصوصية المنطقة وتعدد

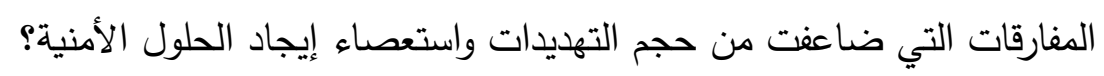

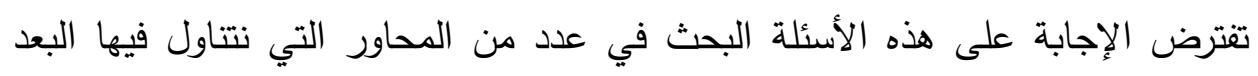

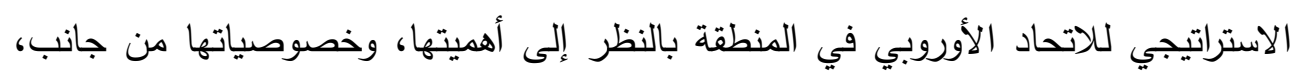

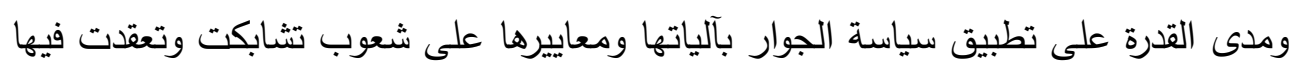

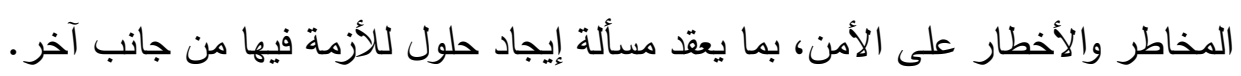

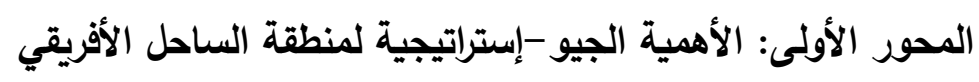

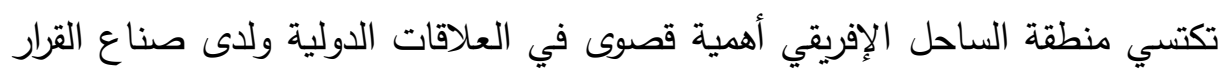

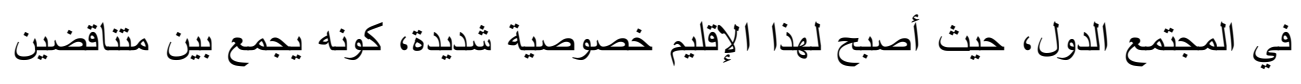

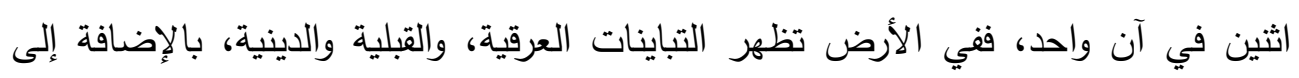

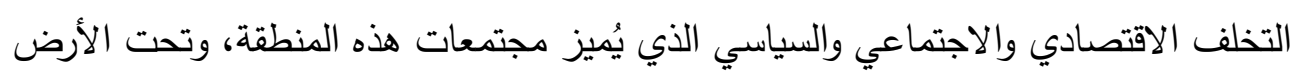

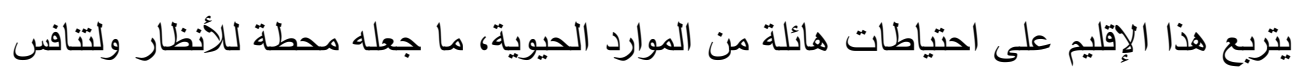

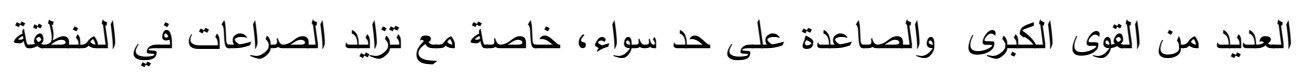

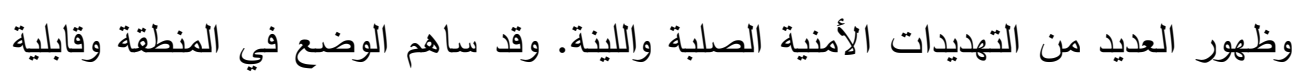

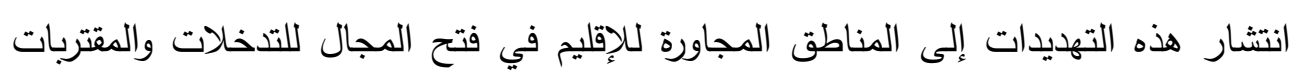
الدولية لإيجاد حلول محتملة للوضع في المنطقة.

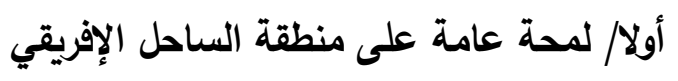

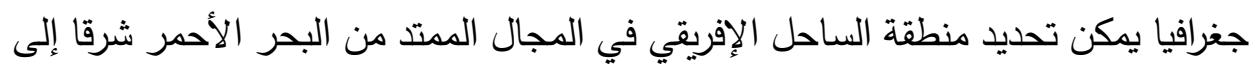

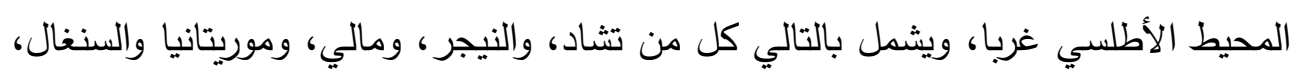

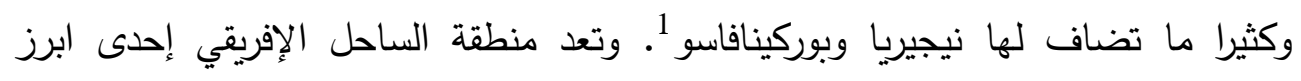

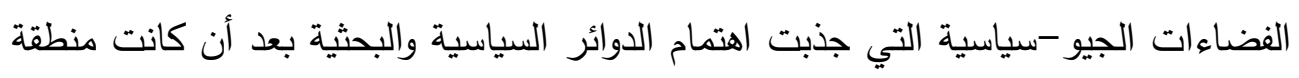

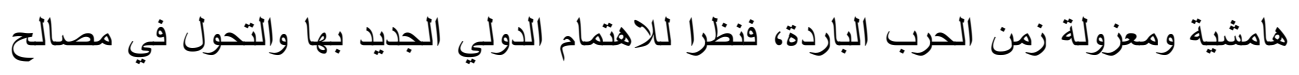

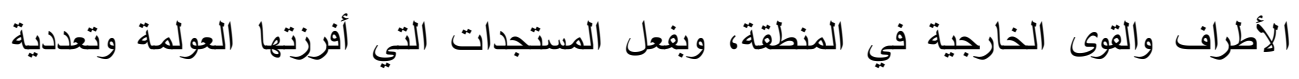

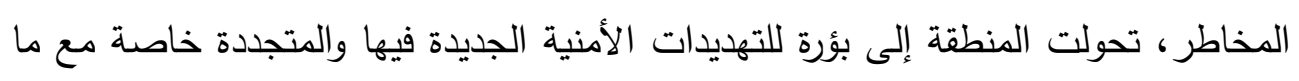
يميزها من خصائص ومنهاج

1- أنها إقليم يستلهم وظيفته الجيو - سياسية من هشاشة ومسامية الحية الحدود بين دوله، وكذا

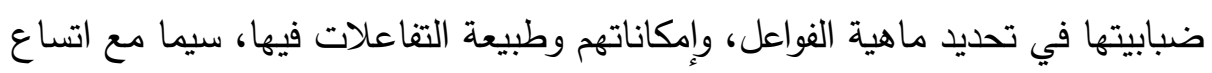


الرقعة الجغرافية مقابل ضعف في الكثافة السكانية التي لا تتجاوز شخصا أو اثثين في الكيلومتر المربع الواحد، وأين يتمركز السكان جنوبا في حين تمثل الصحراء الكبرى معظم موريتانيا، ومالي وتثاد.

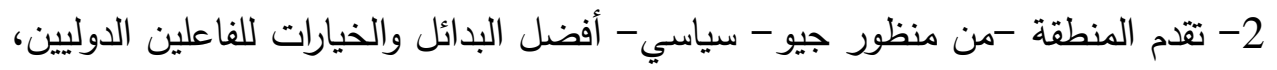

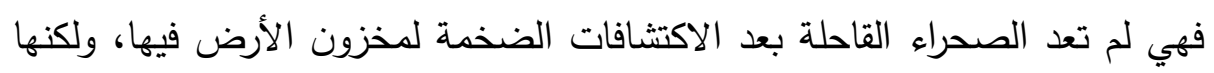
أضحت من أغنى المناطق بالموارد الطاقوية كالبترول والغاز واليورانيوم وغيرها، ومن الأندان ثمة صارت مسرحا جديدا للتنافس الاستراتيجي السياسي والاقتصادي.

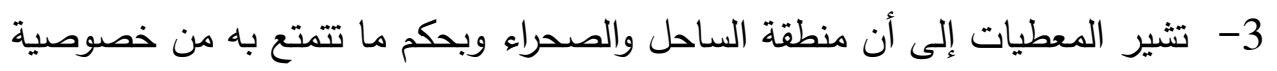
تحولت إلى فضاء استراتيجي ومنطقة عبور مثالية لمختلف أشكال التجارة المحظورة

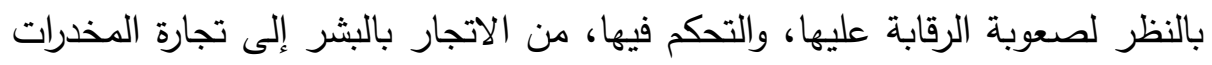
والسلاح 3 وغيرها من أشكال الجريمة المنظمة والعابرة للحدود. ثانيا/طبيعة التهايدات الأمنية في الساحل الإفريقي

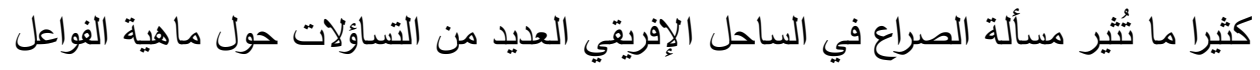

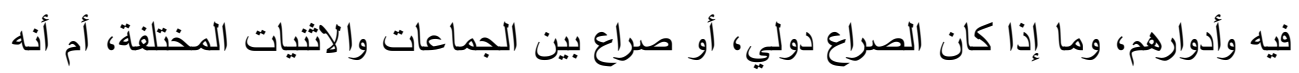

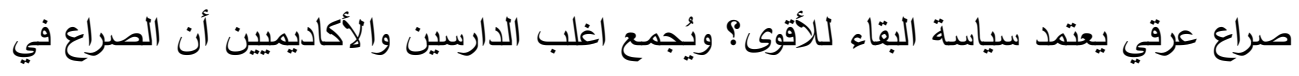

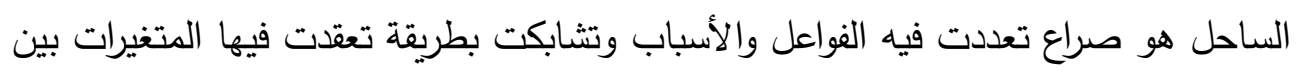

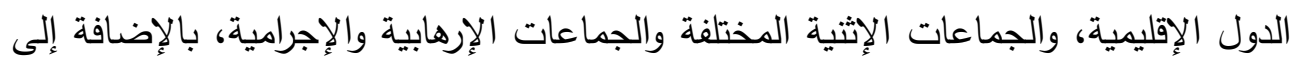

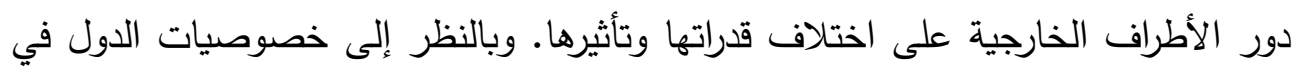

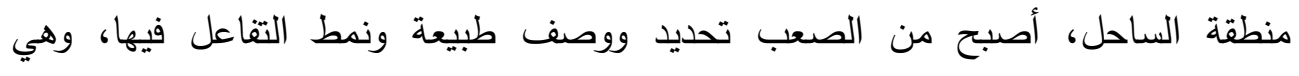

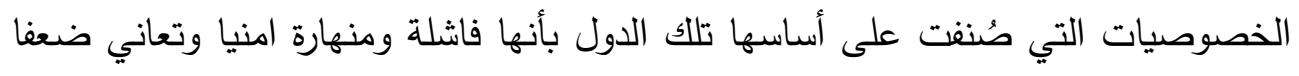
شديدا في مختلف هياكلها ومؤسساتها. كما أن اقتصادياتها هشة وتعاني من التبعية المفرطة

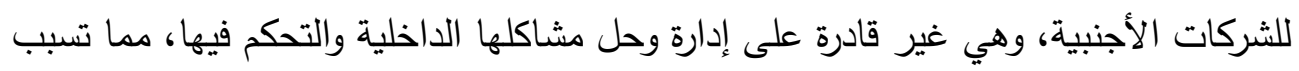

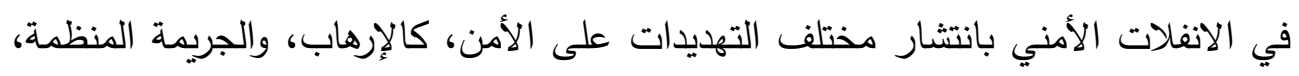
والهجرة غير الثرعية وغيرها من المخاطر على الأمن المجتمعي للإقليم ودوله.

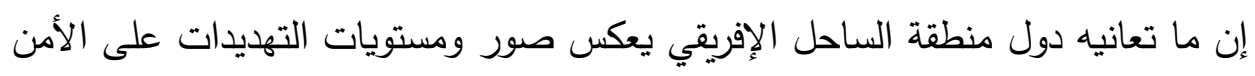

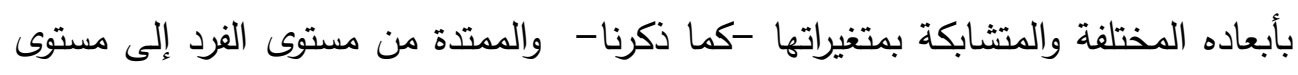

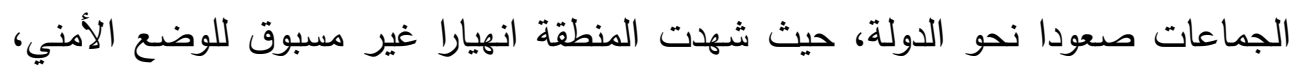

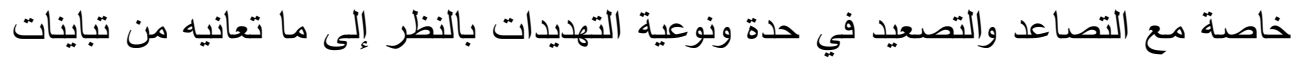


اثثية ومناطقية عززت من الاختلافات والفروقات الاجتماعية والبنيوية وزادت من تأزم الأوضاع السياسية. ونذكر من أهم تلك التهديدات ما يأتي:

- التهايدات الإرهابية: على غرار عوامل الضعف التي تتسم بها منطقة الساحل الإفريقي

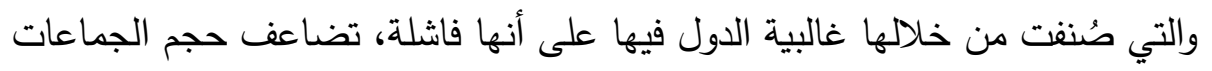

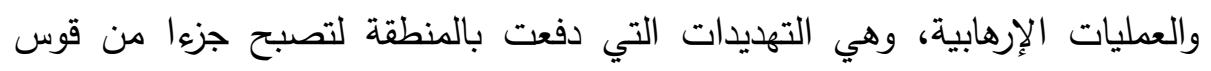

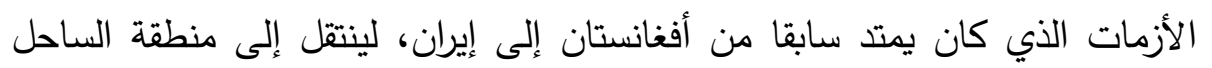

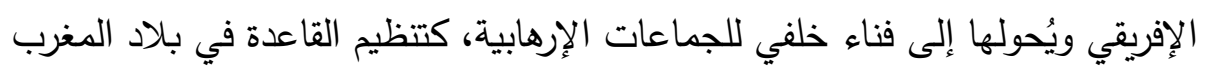

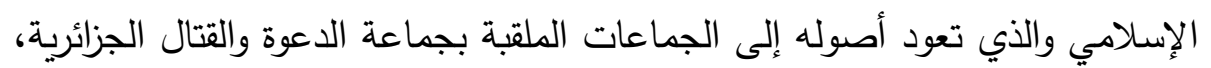
وانتشر أعضاؤه في الصحراء والساحل منذ صيف 20034. كذلادي اللك جماعة بوكو حرام التي تُمثل أكبر تهديد لدول المنطقة كنيجيريا والكاميرون، و "جماعة نصرة الإسلام" وندام

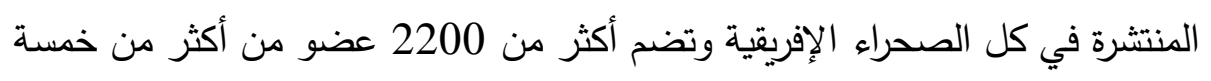

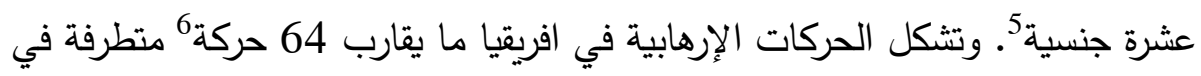

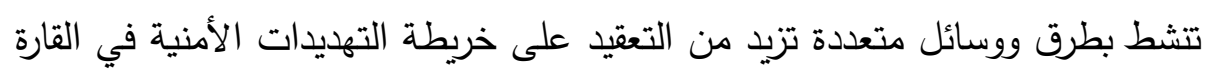

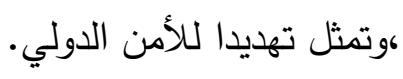

- الجريمة المنظمة وتجارة السلاح والمخدرات: تعتبر إفريقيا عموما ومنطقة الساحل على

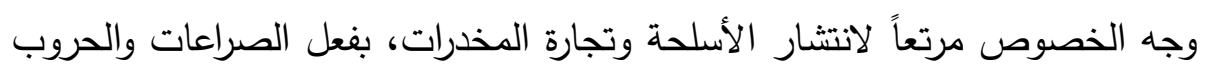

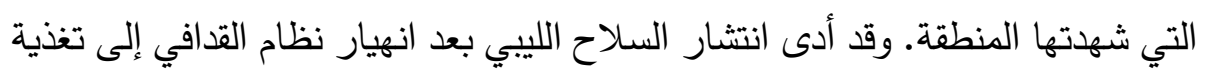

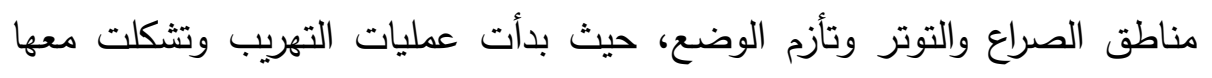

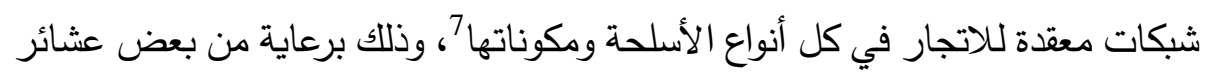

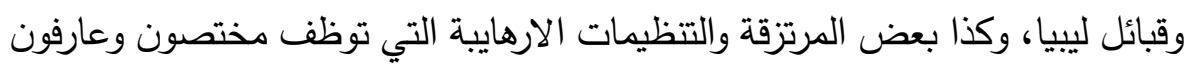

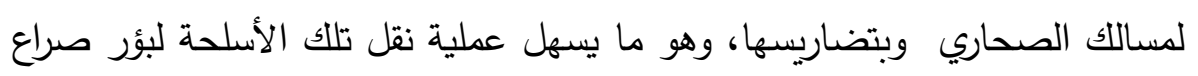

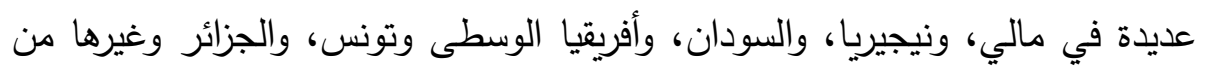

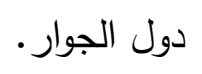

تضاعفت أخطار الجريمة المنظمة مع تحول شبكات التهريب إلى بنى مؤسسية كبيرة

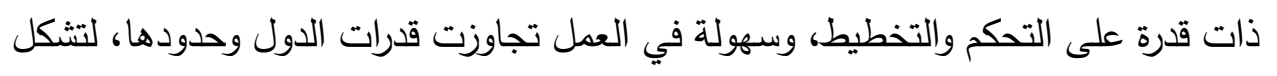

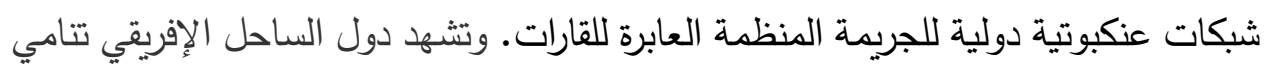

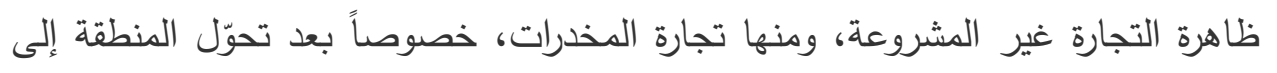


مكان عبورٍ للمخدرات الصلبة، كالهيروين والكوكايين والكراك، من أمريكا اللاتينية إلى أوروبا عبر إفريقيا الغربية ثم الساحل الإفريقي، وعبر المغرب العربي.

- الهجرة غير الثرعية: تعرف افريقيا وكالعديد من المناطق ارتفاعا ملحوظا لعدد

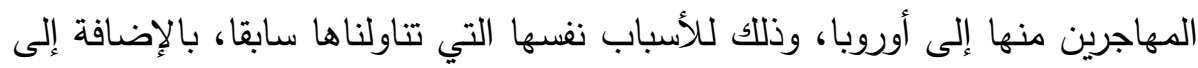

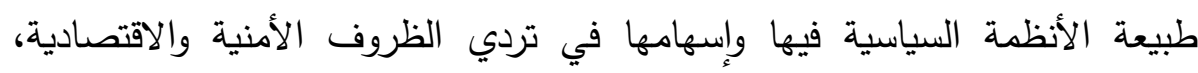

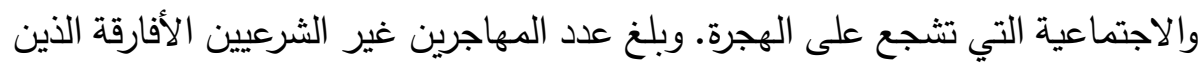

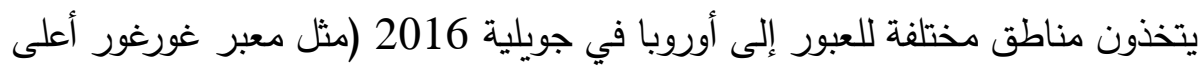
المغرب، أو عبر البحر المتوسط انطلاقاً من ليبيا والجزائر ، مروا عبر ليبيا إلى إيطاليا)

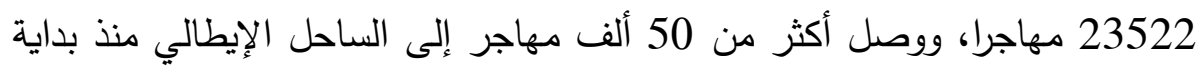
عام 2017، بينما غرق أكثر من 1400 مهاجر، ومن بين 181.000 مهاجر دخلوا

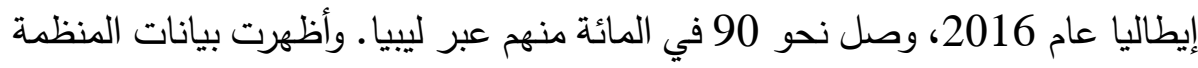

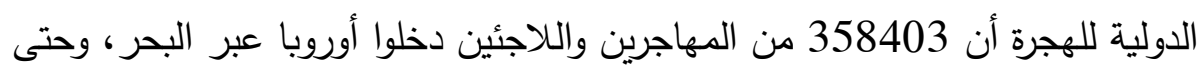
21 ديسمبر 2016 وصل معظمهم عبر اليونان وإيطاليا8.

تؤكد هذه الأرقام مدى خطورة ظاهرة الهجرة على الأمن أوروبا، لكنها توضح ضرورة

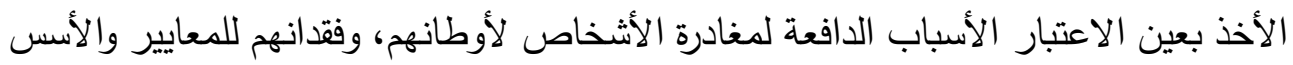
التي تُبقي على حياتهم في ظل تراجع دور ووظيفة دولهم الأصلية في تحقيق أمنهم واستقراره.

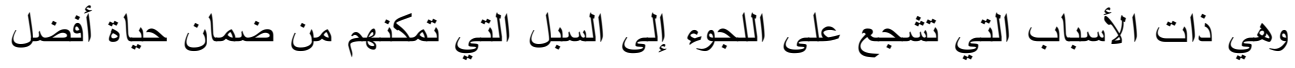

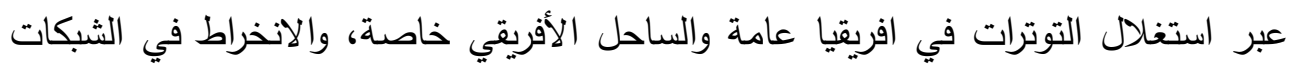

$$
\text { الإجرامية والحركات الإرهابية. }
$$

- التهايدات الجديدة على الأمن: كان للتغير الذي شهده حقل العلاقات الدولية في فترة

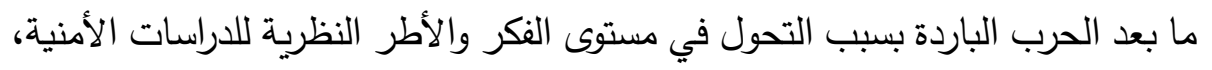

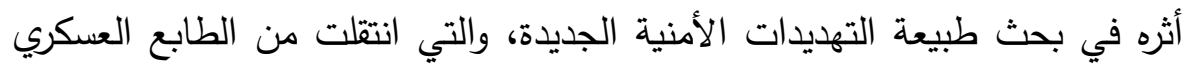

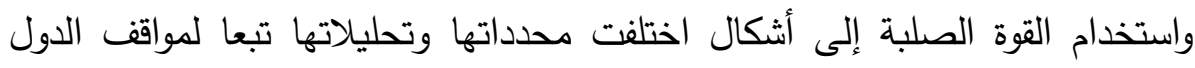
الضيقة وحسب تصور وإستراتيجيات القوى الكبرى. فقد تجاوز التهديد سيادة الدولة

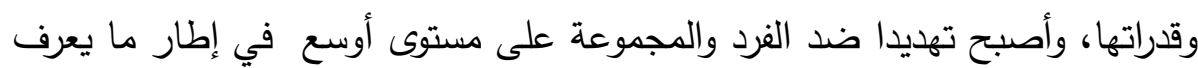

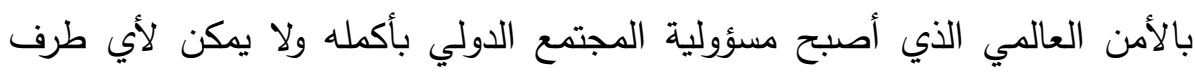

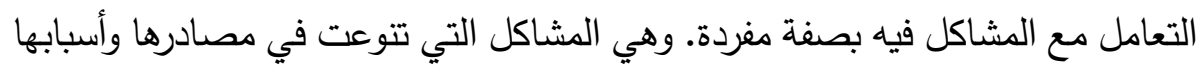
وكيفية التعامل معها، فلا يمكن تحديد وضبط كل أشكال العنف ووصف أسباب التهديد 
بصفة مؤكدة خاصة وقد تحولت الدول القومية نفسها إلى مصدر من مصادر التهديد

على مواطنيها وهو ما تُؤكده مقاربة الدولة الضعيفة 9.

أدت التغيرات التي طرأت على النظام الدولي إلى تفكلك العديد من الدول وتفاقم إثكالية الحديث عن مستقبل الدولة القومية وعلاقاتها بقضـايا الأمن الإنسـاني والعالمي. ويرى العديد من الدارسـين أن مقاربة الدولة الضــيفة هي تأكيد على أهمية دور الدول الكبرى وضــرورة اسـتقرار النظام الدولي، خاصــة وأن غالبية النزاعات التي تعرفها منطقة الســاحل الأفريقي كانت بفعل ظهور الدول الضـعيفة والعاجزة حسب تصورهم. وتُعرف الدولة الفاشلة على أنها "تلك التي تفقد الســـيطرة على وســـائل العنف الخارج عن الإطار القانوني، ومن ثمة تكون عاجزة عن تحقيق السـلام والاسـتقرار لشـعوبها وفرض السـيطرة على أراضـيها فلا تســطيع ضمان النمو الاقتصادي أو أي توزيع عادل للسلع الاجتماعية. وغالبا ما تتميز السلطة فيها

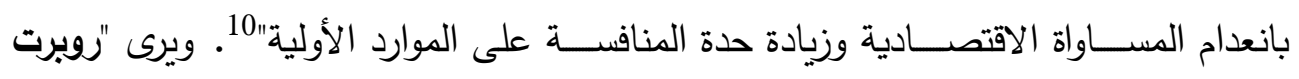
روبنزغ" مدير "برنامج الصـراع بين الدول" في الأمم المتحدة أن الدولة القومية فشلت لأنها لم تعد قادرة على توصـيل أهم السـلع السـياسـية والايجابية لثـعوبها، وهي ســع الأمن والتعليم والصــحة والفرص الاقتصــادية، والرقابة البيئية، وإطار قانوني للنظام العام ونظام قضــائي لإدارتها11. وهو حال غالبية الدول في منطقة السـاحل الأفريقي التي تعاني تدهورا اقتصـاديا مركبا وتراجعا في مستوى التتمية وضمان التوزيع العادل للثروة، وهو مؤشر مؤسس لوضعية

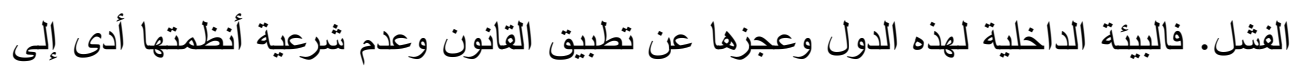
حدوث انكثــــاف أمني لها وفتح المجال لكل الظواهر المهددة للأمن ومنها التدخلات

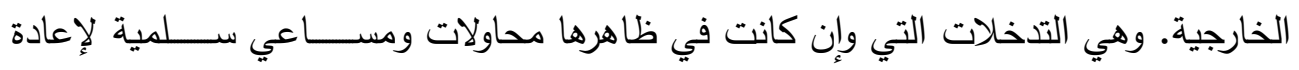
الاسـتقرار في منطقة السـاحل الأفريقي، إلاً أنها سـاهمت في تأزم الوضـع أكثر وهذا بالنظر

$$
\text { إلى طبيعة المنطقة وخصوصياتها (الوضع في ليبيا اليوم). }
$$

\section{المحور الثاني: استراتيجيات الاتحاد الأوروبي لصنع الاستقرار في منطقة الساحل الأفريقي}

إن الحديث عن وجود أبعاد إستراتيجية وسياسات بأهداف غير معلنة تتماشى ودستجدات الوضع في النظام الدولي وما تبعها من تحولات على مستوى المفاهيم والآليات، دفع بالاتحاد الأوروبي وكفاعل في العلاقات الدولية إلى تبني مفهوم وصيخ الأمن الإنساني بكل محتوياته

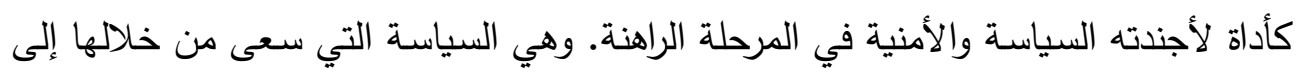
نشـــر ثقافة مغايرة لثقافة الهيمنة والتدخل في الثـــؤون الداخلية للدول، والعمل على تحقيق 
وصـــناعة الاســتقرار في مناطق الأزمات والتوتر ـ الأمر الذي تطلب تحمل المزيد من

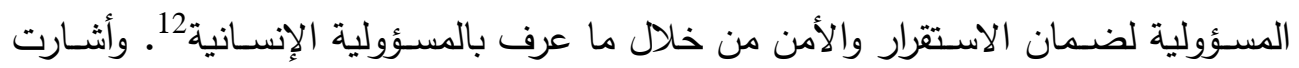
وثيقة الاتحاد الأوروبي إلى أن الأمن الإنساني هو مسؤولية تاريخية مشتركة تقع على كاهل

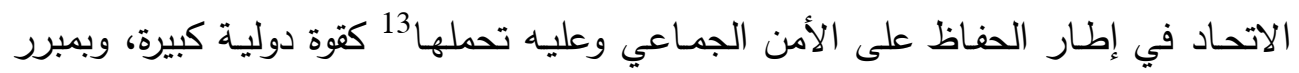

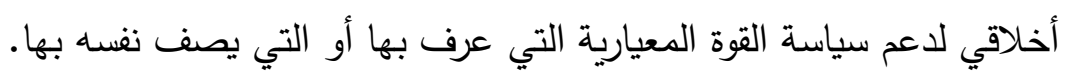

فما هي أسس ومبادئ هذه القوة؟ وإذا كان الاتحاد الأوروبي هو فعلا قوة معيارية فهل

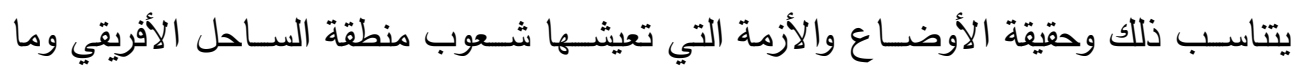

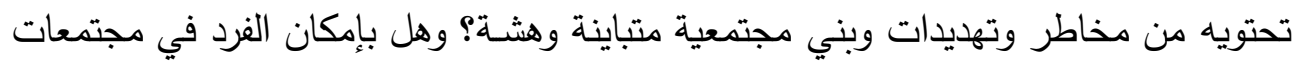
تفتقر إلى متطلبات الحقوق الإنسانية أن يتبنى معايير وسياسات لا تعبر عن انتماءه وتمايزه واختلافاته كأفريقي؟ هذا ما سـنتناوله في هذا المحور من خلال وصـف الاتحاد الأوروبي كقوة معيارية ولجوءه

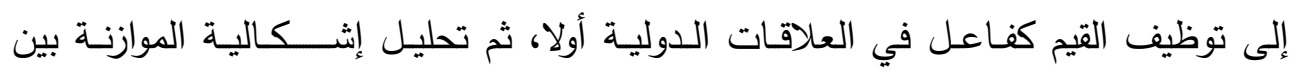

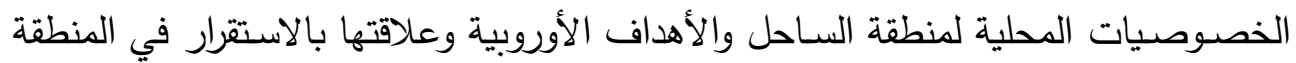

أولاً/ سياسة الجوار الأوروبية وتوظيفها في دول جنوب الصحراء والساحل:

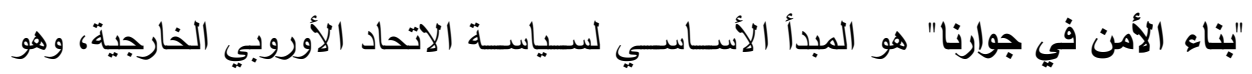

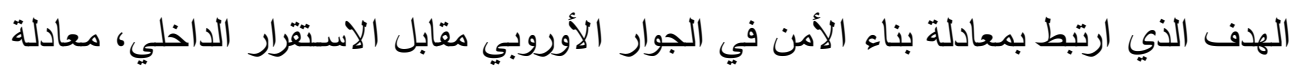

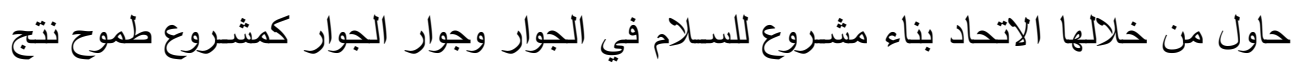

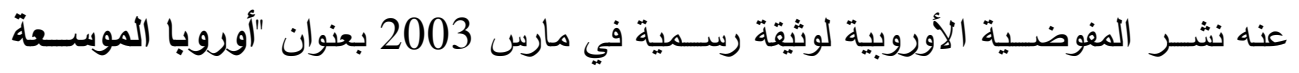

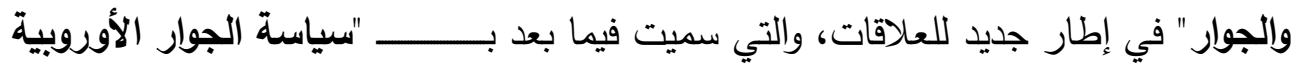

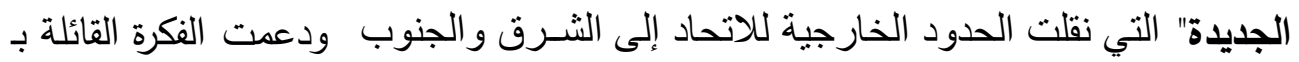
"أوروبا قوة معيارية". وهي الفكرة التي أثارت عديد النقاشات والحوارات.

كثر في السنوات الأخيرة الحديث عن أوروبا كقوة معيارية وبوسائل وآليات سلمية وغير عسكرية لكن هذه النظرة عن أوروبا كقوة لينة رفضها الواقعيون ومنهم "هادلي بال" (BULL Hadley)

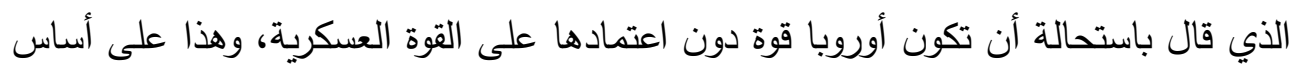

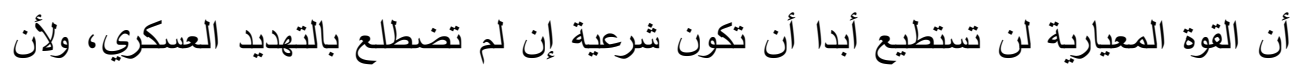

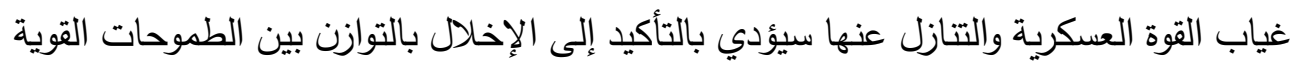


والإمكانات الفعلية الضعيفة14. وتعود فكرة القوة المعيارية إلى أفكار "إدوار كار" ( CARR

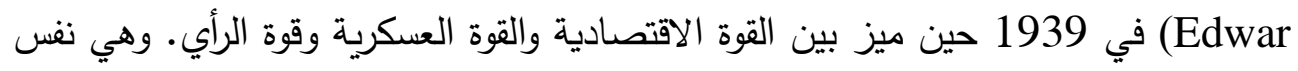

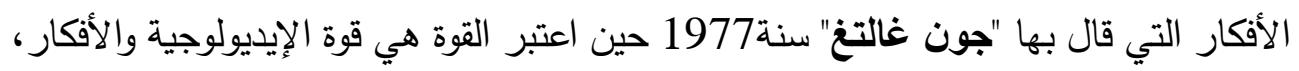

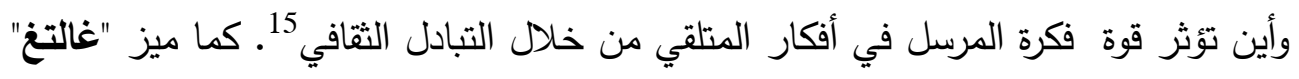

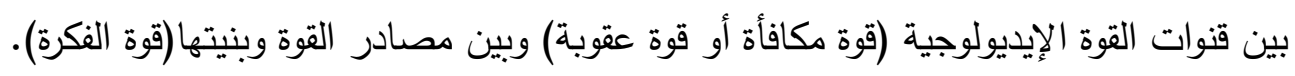

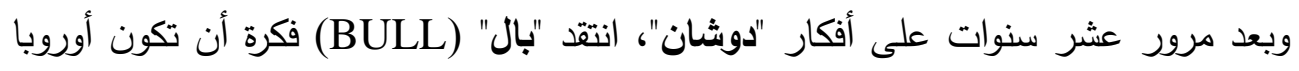

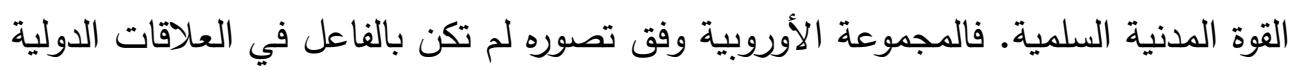

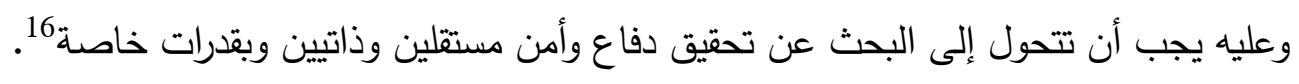
وانبثق مفهوم القوة المعيارية من النقاش حول قوة الفكرة والرأي وعلاقة مصالح الفواعل بهذه دونه

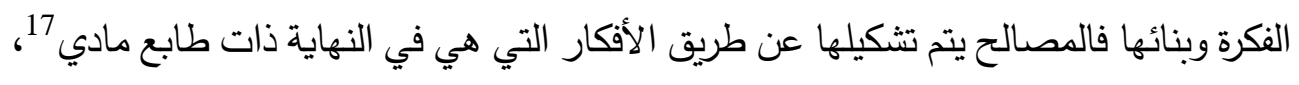

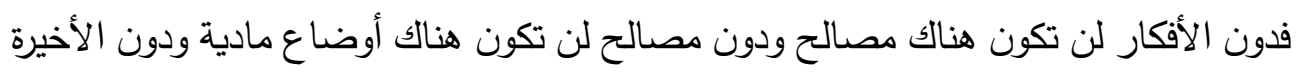

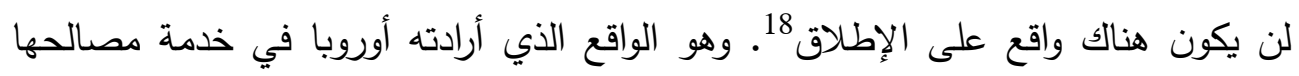
وأهدافها في منطقة الساحل الأفريقي والصحراء.

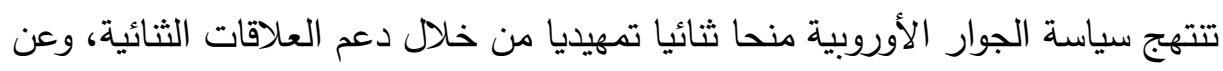

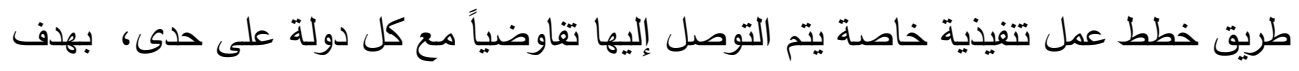

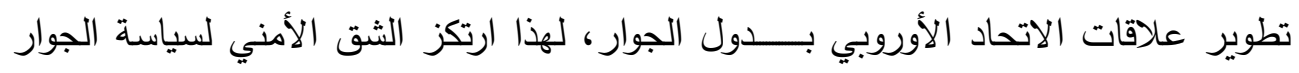

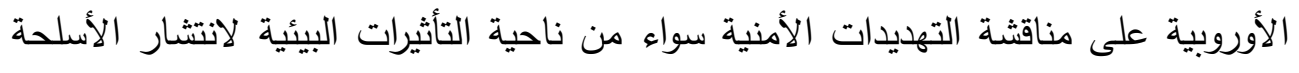

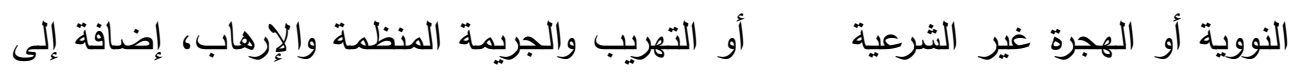

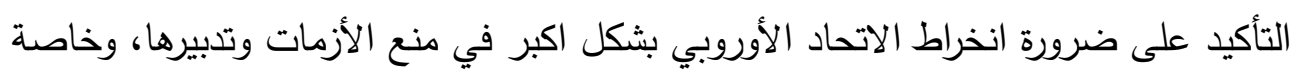

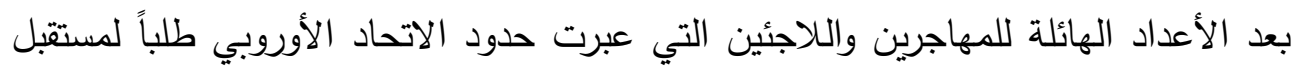

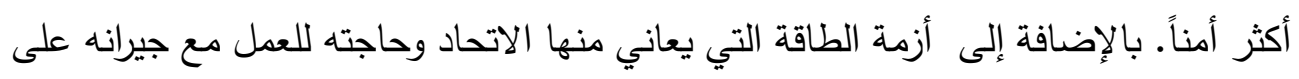
تحقيق أمنه الطاقوي عبر سياسة الجوار الموجهة إلى دول جنوب الصحراء وشمال إفريقيا وسعيه لتلقين معاييره وقيمه في تحقيق الديمقراطية، وحقوق الإنسان، وحكم القانون والانفتاح

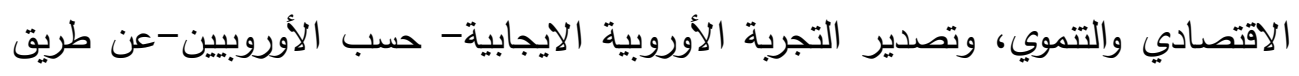

أدوات "القوة الناعمة" (Soft Power).

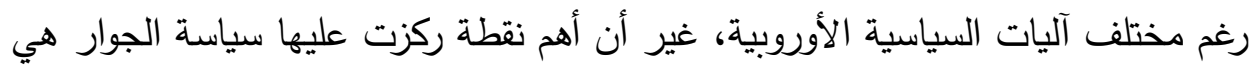

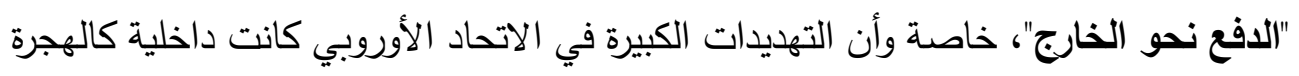

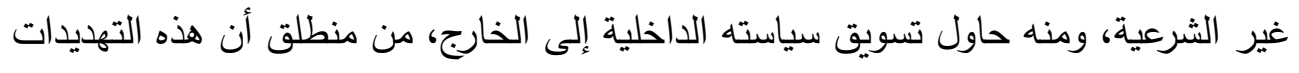

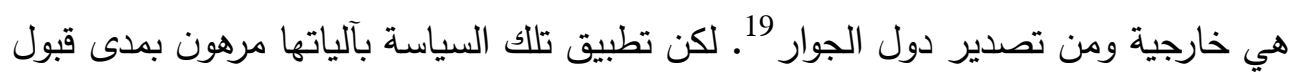


الأفارقة والجماعات في دول المنطقة لأفكار غربية دخيلة على تصوراتهم، ويبقى نجاح القيم

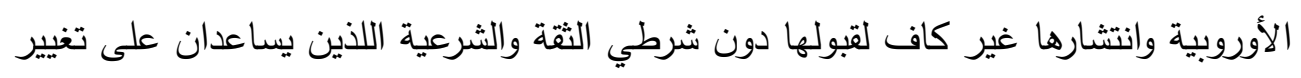

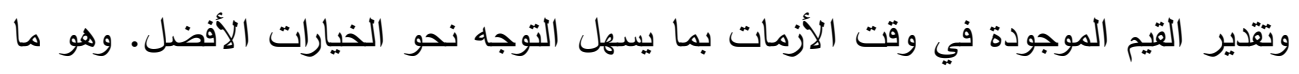
تُعرفه البنائية بنافدة الفرص (Window of opportunity) التي تُمكن من بحث وتفيم وتفهر

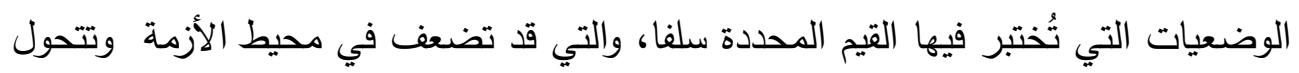
ليتحول معها الوضع السابق. شرط آخر لنجاح انتشار القيم والمعايير هو إتقان التلقين الاجتماعي (Socialization)، فحتى لو لم يكن هذا المسار ضروريا لاستمرار الإتحاد وبنائه فإنه يبقى بالنسبة للبنائية مهما في توسيع قيمه، وذللك عبر تثفيرها (codification)

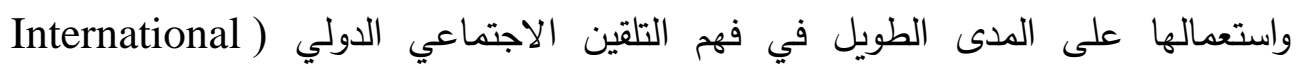
Socialization

ثانياً/ الامتداد التاريخي لعلاقات الاتحاد الأوروبي بدول شمال إفريقيا والساحل:

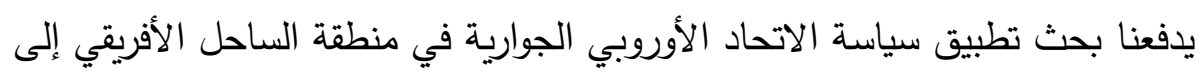

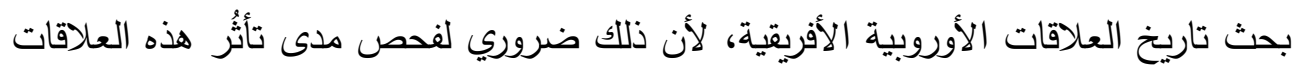

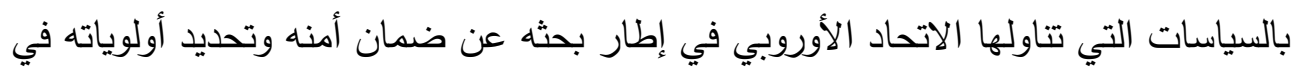

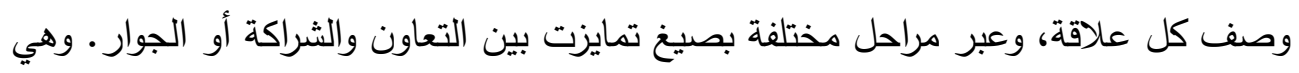

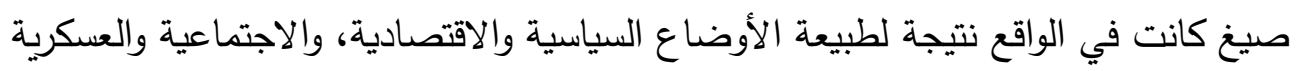
داخل البيت الأوروبي، والتي فرضت التيجة لطيعة كل شكل أو نموذج علائقي خصوصيات معينة.

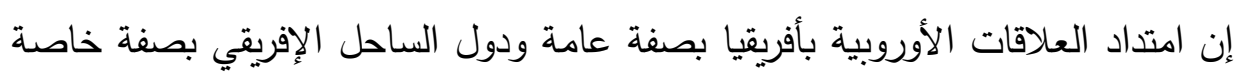

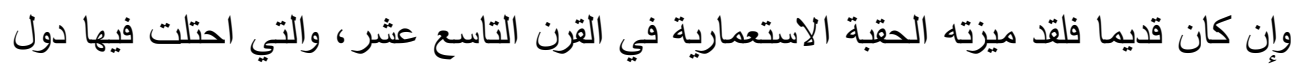

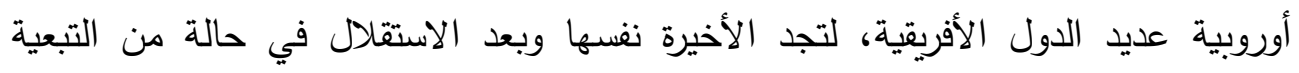

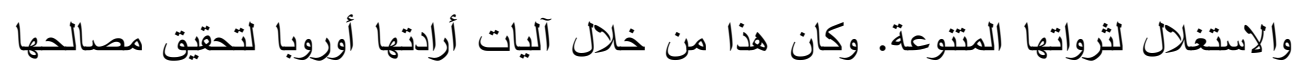

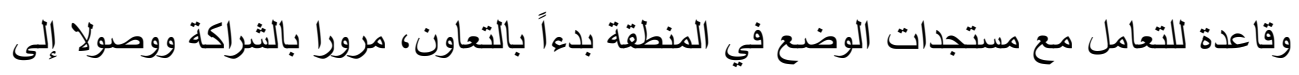

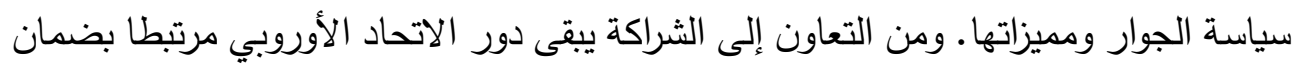

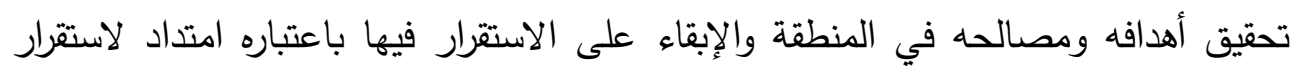

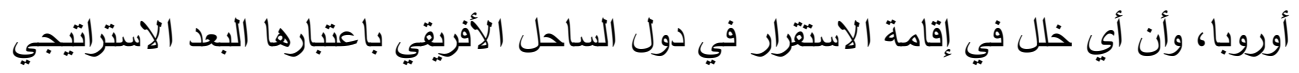
للأمن الأوروبي هو اختلال للتوازن والاستقرار في أوروبا.

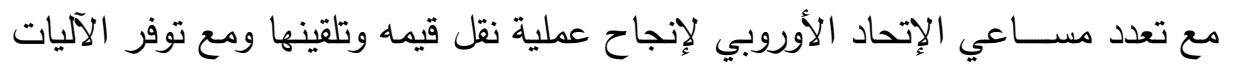

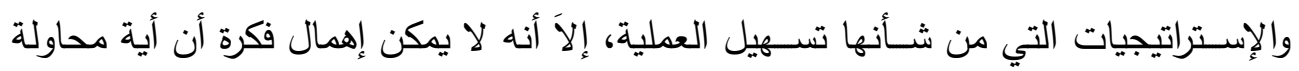


للإصــلاح -وإن كانت مرنة وسـمية- فقد تتطوي على احتمال الفشـل. وقد يكون ذلك سببا

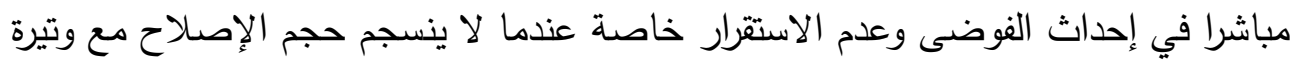

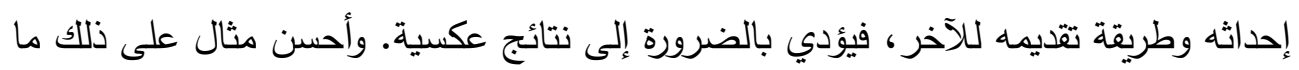
حدث في بعض البلدان العربية التي أدت فيها الرغبة الملحة للتحول الديمقراطي إلى إغفال

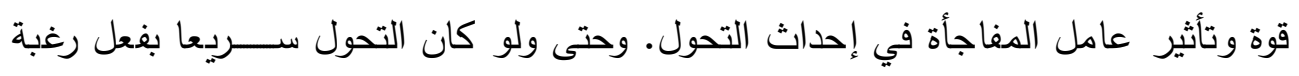

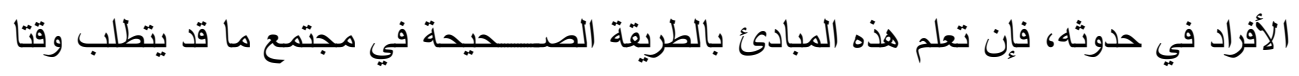

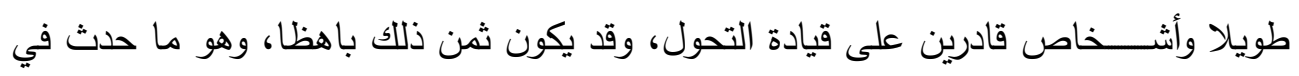

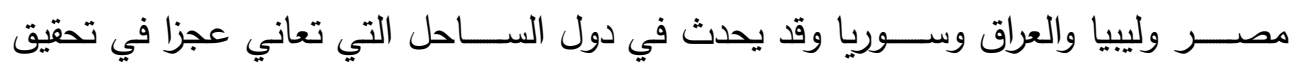
الانسجام بين الأقليات فيها.

مع تأزم الوضع في منطقة الساحل الأفريقي زاد اهتمام الاتحاد الأوروبي بمسألة

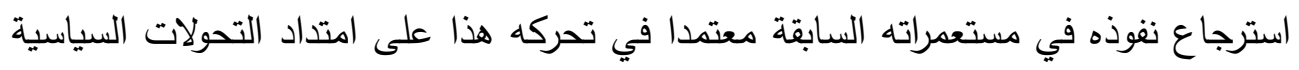

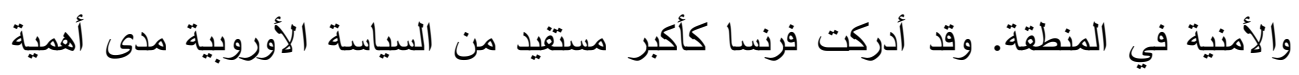
تواجدها في المنطقة، وهذا يكثف بالدرجة الأولى مدى إدراكها لمركزية الساحل الإفريقي

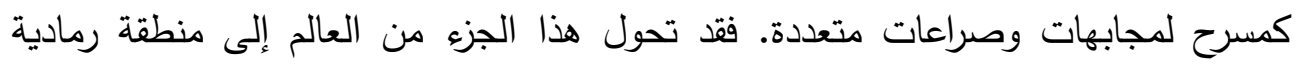

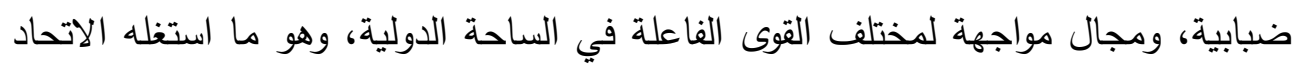

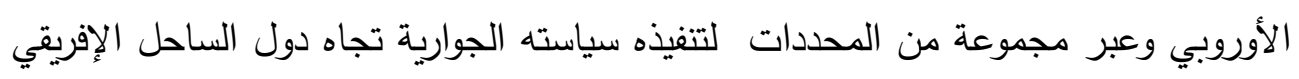
وكذا شمال إفريقيا ومن بين هذه المحددات ما يلي 21:

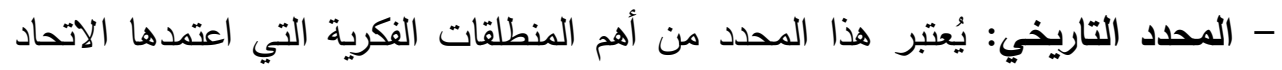

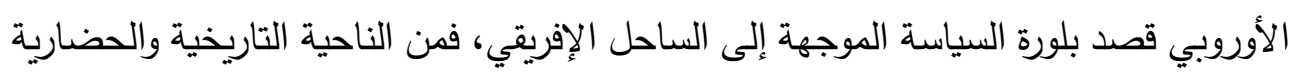

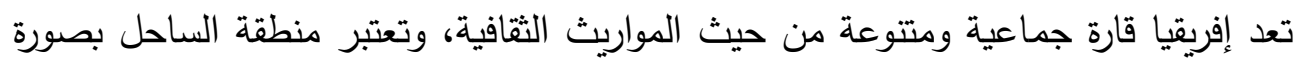
خاصة الفناء الخلفي لدول الاتحاد الأوروبي.

- المحدد الجيو - استراتيجي: مثل امتداد منطقة الساحل الكبير من غرب إفريقيا إلى شرقها

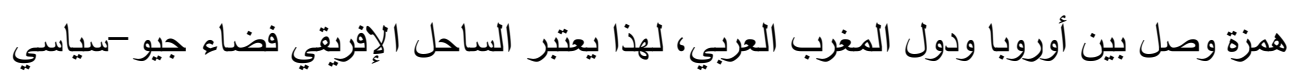

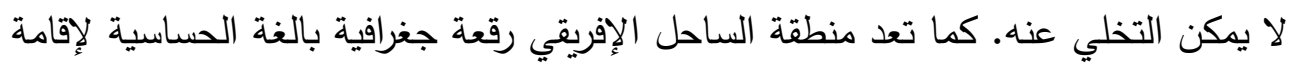

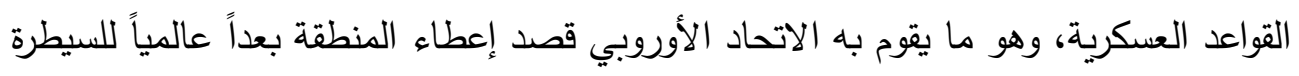

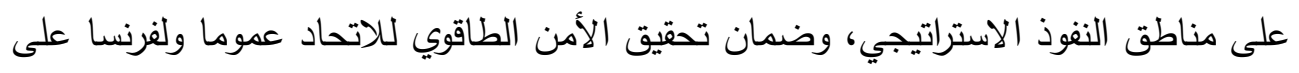


- المحدد الأمني: اعتمد الاتحاد الأوروبي في بلورته للإستراتيجية المتعلقة بالساحل الإفريقي

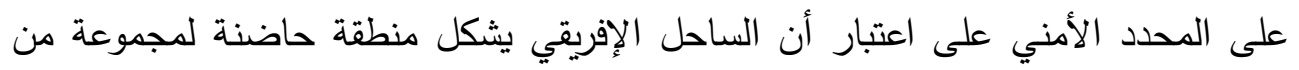

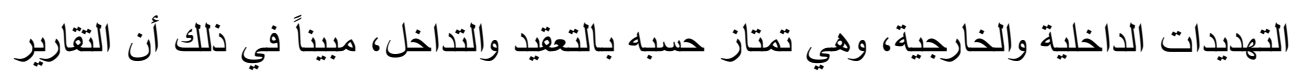

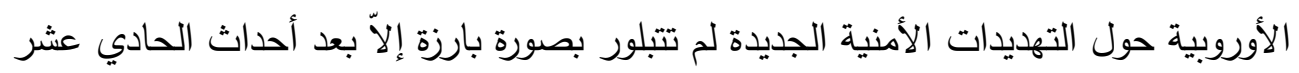

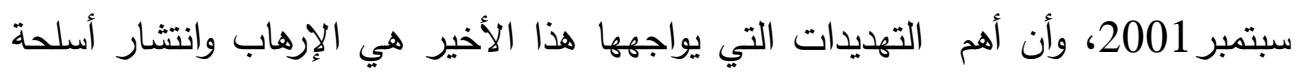
الدمار الثامل والجريمة المنظمة والهجرة غير الثرعية.2001، وان التهات

- المحدد التنافسي: في إطار التتافس بين القوى الكبرى على التمركز في منطقة الساحل

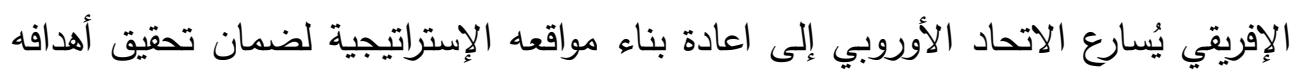

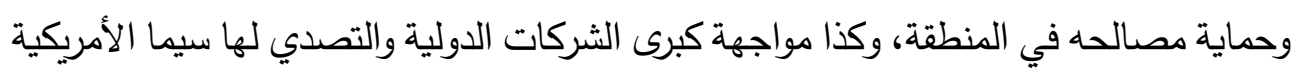
منها

من خلال بحث هذه المحددات يمكن القول أن مساعي الاتحاد الأوروبي للحفاظ على الإنى

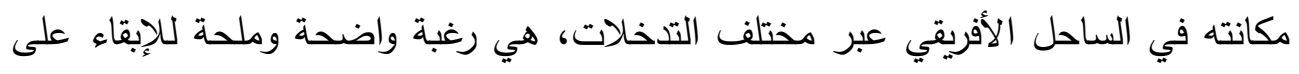

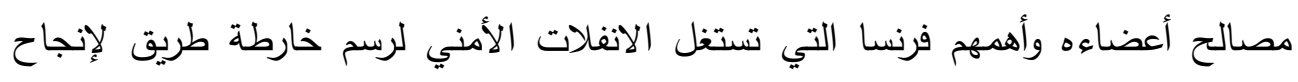

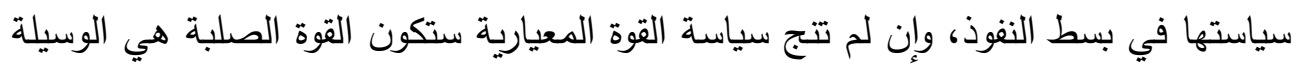
لذللك.

\section{المحور الثالث: الآليات المتبعة في تنفيذ السياسة الجوارية في دول الساحل الإفريقي} يتطلب نجاح دور الاتحاد الأوروبي في ترسيخ الاستقرار في دول الساحل الأفريقي التحول

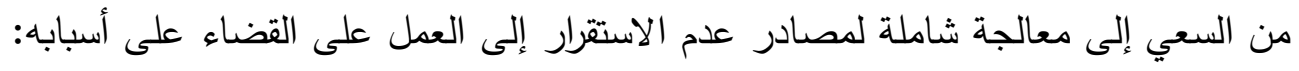

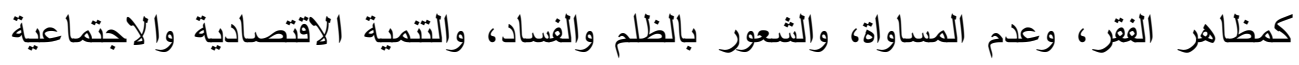

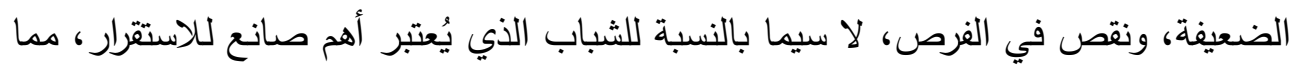

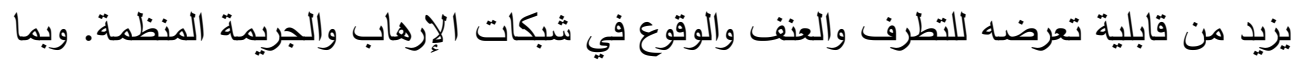

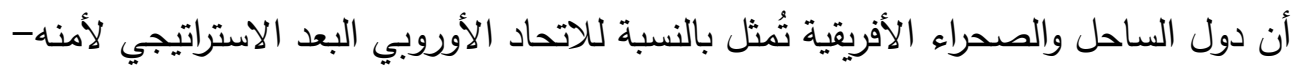

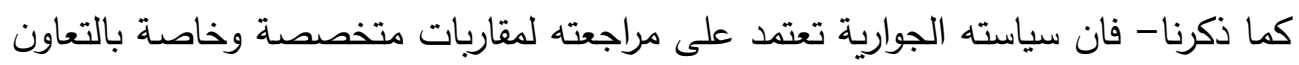

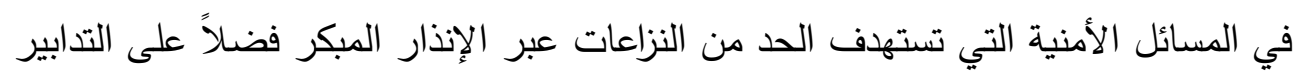

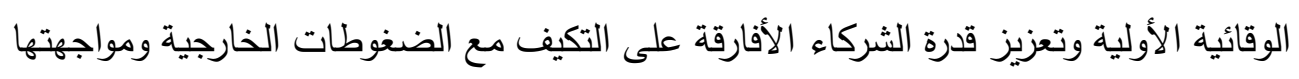

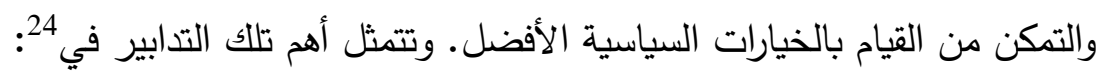


أكد الاتحاد الأوروبي أن عليه المحافظة على القيم العالمية وتعزيزها من خلال السياسة

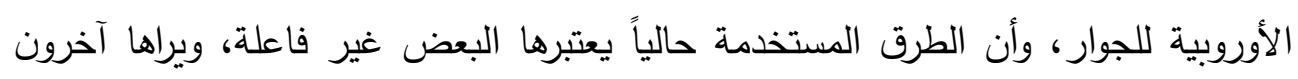

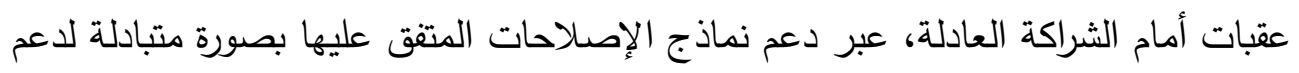

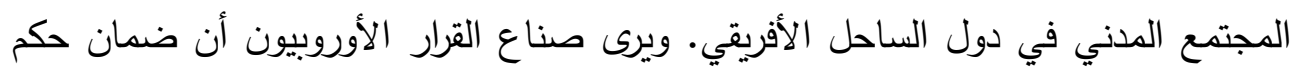

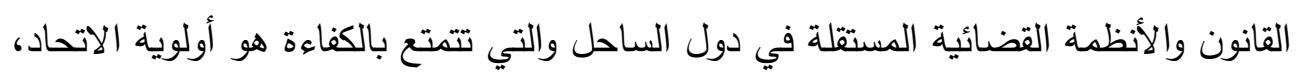

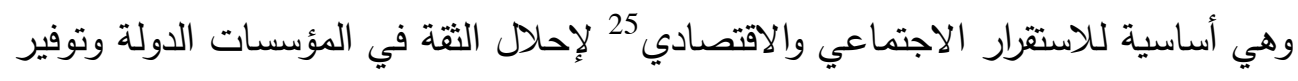

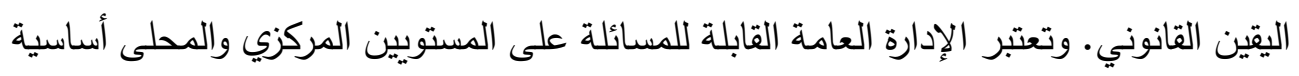

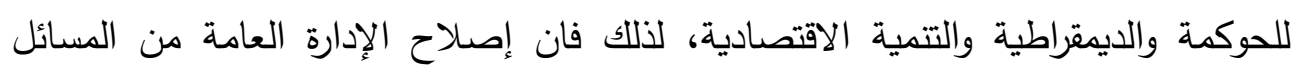

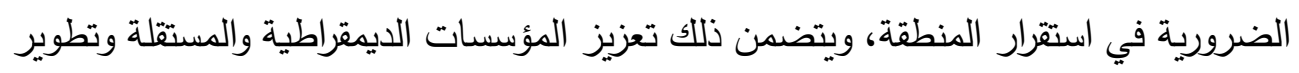

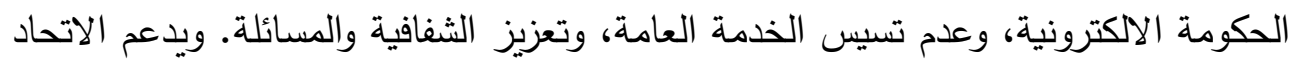

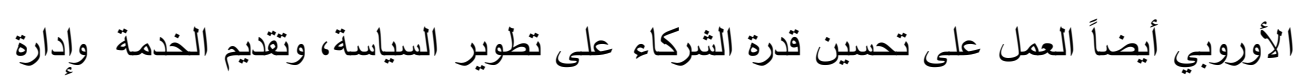

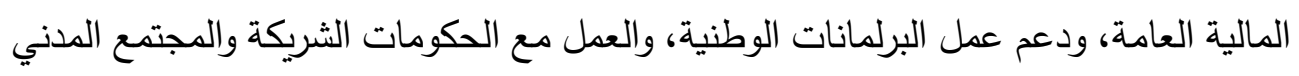

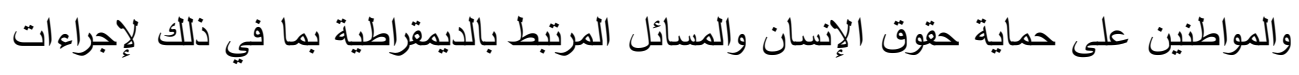

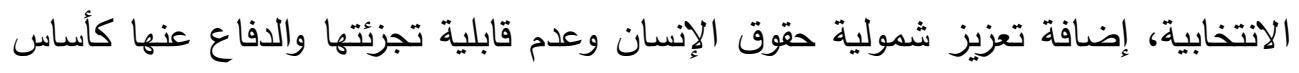

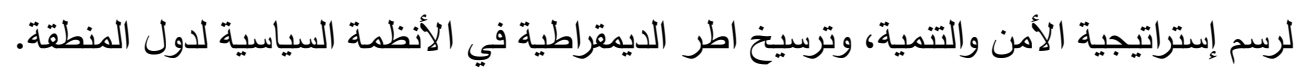
ولكن رغم بعض محاولات الاتحاد الأوروبي للانتقال بدول الساحل نحو الديمقراطية، إلاّ أن الوضع السياسي يعاني الكثير من النقائص على صعيد طبيعة أنظمة الحكم غير الثرعية.

\section{2_ التنمية الاقتصادية وصناعة الاستقرار في الجوار:}

يُعتبر الاتحاد الأوروبي كثريك في التتمية الاقتصادية والتحديث والاستثمار وتطوير

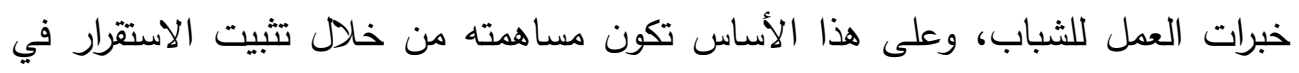

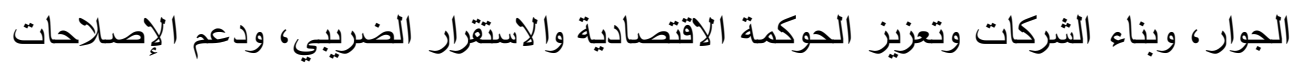

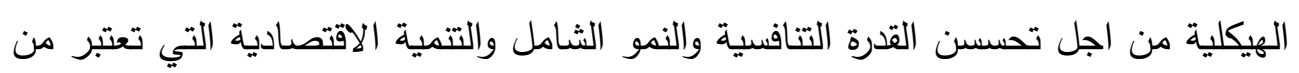
الأمور الأساسية لتطوير القدرة الاقتصادية لبلد معين على التكيف والتعافي 26.

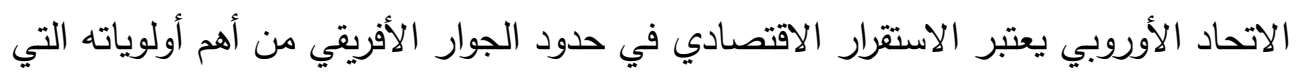

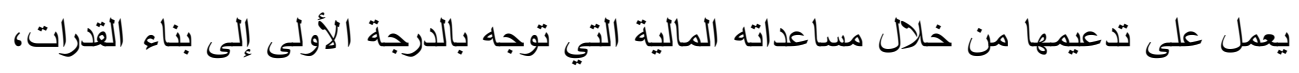

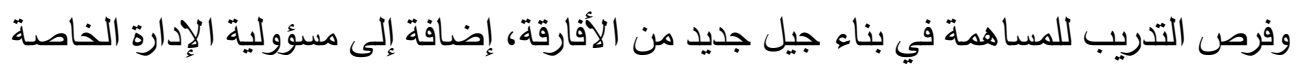

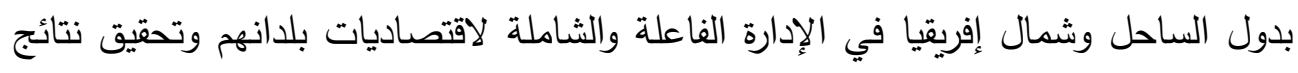


اجتماعية مستدامة تعمل على تحديث الاقتصاد وتحفيز الابتكار واستحداث وظائف ودعم

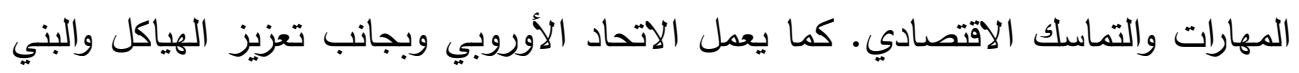
الاقتصادية والاجتماعية على خلق فرص جديدة للعمل من اجل الجماعات المهشمة اجتماعياً

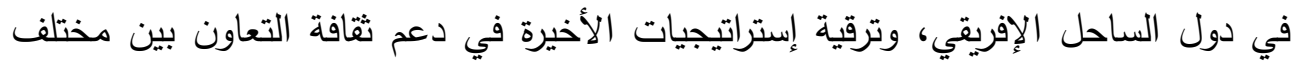

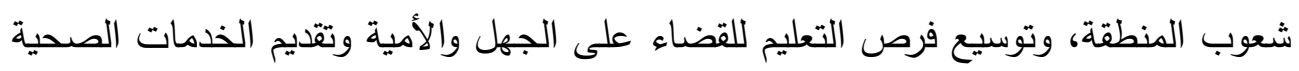

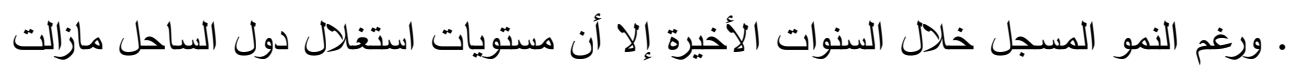

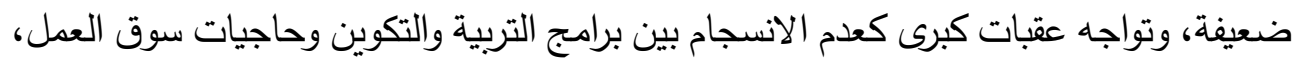

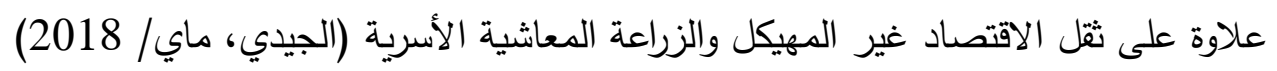

\section{3_ تحقيق التنمية المستدامة:}

يهدف الاتحاد الأوروبي من خلال سياسة الجوار إلى العمل مع جيرانه على تحديث

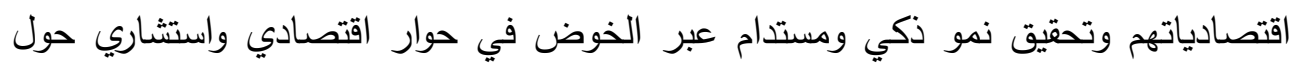

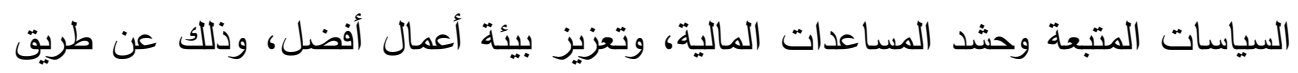

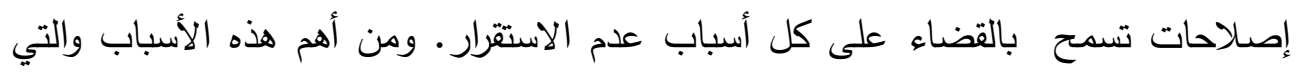
تشكل في حد ذاتها أهدافا للتمية ما يأتي(Think Thanks francais, 2019) :

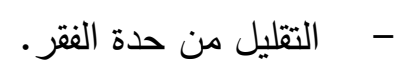

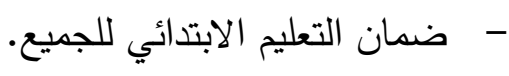

- - دعم المساواة بين الجنسين وتمكين المرأة في المجتمعات الأفريقية.

$$
\text { - تقليص نسبة وفيات الأطفال. }
$$

- - محاربة انتشار فيروس الايدز، وكل الأمراض المعدية.

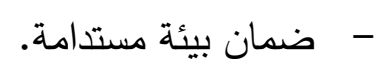

- - - مدمان تحقيق شراكة دولية للتنمية.

بجانب وصف هذه الأهداف أكدت لجنة الاتحاد الأوروبي في اجتماع لها في بروكسل

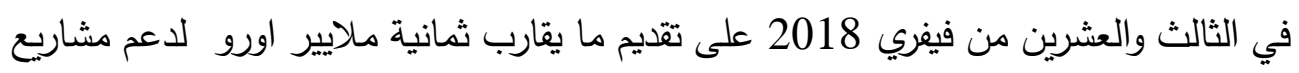

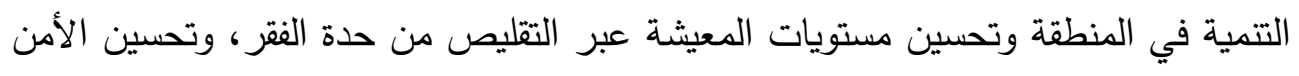

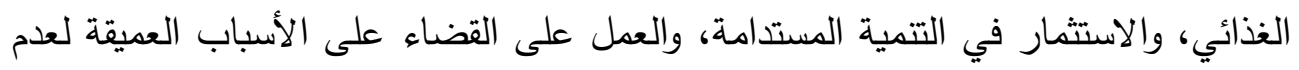
الاستقرار، وخلق فرص للشباب من خلال تطوير البنى التحتية ودعم الاقتصاد 
(https://eeas.europa.eu/csdp-missions-operations/eucap-sahel,

\section{4_ التعاون الجواري في المجالين الطاقوي والتجاري:}

عمل الاتحاد الأوروبي على دعم التعاون في مجال الطاقة مع دول الساحل ومنها موريتانيا مالي، والنيجر، والتشاد، وهو تدبير امني بالنسبة للاتحاد الذي يفتقر إلى مصادر الطاقة بأنواعها، اعتمده لضمان أمنه وضمان ما يُعرف بسيادة الطاقة كوسيلة للتنمية الاقتصادية المستدامة في إطار جديد من التعاون مع الثركاء المحتملين في الساحل الأفريقي بعد الاكتشافات الضخمة لمصادر الطاقة فيها، والتي تدعم مساعي الاتحاد وخاصة فرنسا على تعزيز حوار الطاقة مع تلك البلدان ودعم الطاقة المستدامة فيها. أما فيما يخص القطاع التجاري فتعمل سياسة الجوار الأوروبية على تفعيل النمو الاقتصادي وخلق فرص جديدة للعمل والدفع بعجلة التجارة وترقية المؤسسات المالية، والحد من الفقر في بلدان الساحل الأفريقي

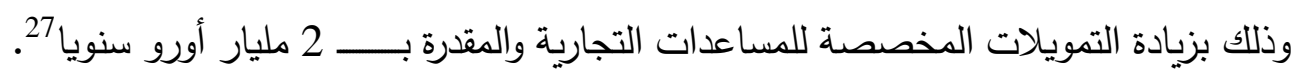
ورغم هذه الأرقام والمساعي الأوروبية، إلاً أن المفاوضات التجارية مع الدول الإفريقية تعاني صعوبات كبيرة، وذللك بسبب عدم تماشي هذه الاتفاقيات مع توجهات منظمة التجارة العالمية

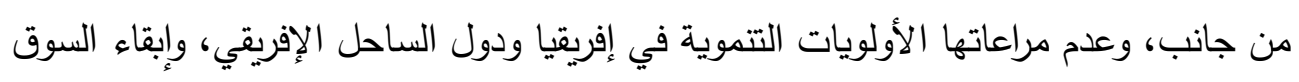
الإفريقية سوق استهلالية للمنتجات الأوروبية فقط من جانب آخر • وهو ما يؤكد فشل السياسة الأوروبية، خاصة وأن الاتحاد الأوروبي لا يعمل وفق سياسة مشتركة وإنما يتباحث ويعمل مع مع ئح كل دولة وفقا لأهدافه لا مصالح تلك الدول، مما ساهم في استفحال الكثير من الأزمات والتوترات: كالأزمة في ليبيا وفي مالي، والتي تدخلت فيها فرنسا لانجاح مخططاتها دون مراعاة لتوجهات الاتحاد الأوروبي

\section{خاتمة:}

من خلال ما تقدم في هذه الورقة وبالنظر إلى كل البرامج الإصـاحية التي قدمها الاتحاد الأوروبي ضنمن سياسته الجوارية، يمكن إجمال بعض النتائج التي تلخص مسار البحث في

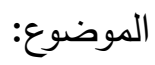

- مهما بلغ حجم المكاسب التي تجنيها دول الساحل الأفريقي من سياسة الاتحاد الأوروبي الجوارية يظل تدخل الأخير في المنطقة جزءا من عملية إعادة هندسة المنطقة بأزماتها 
ومشاكلها وفق ما يخدم ترتيباته لاستغلال ثروات المنطقة ومواردها التي جعلت منها

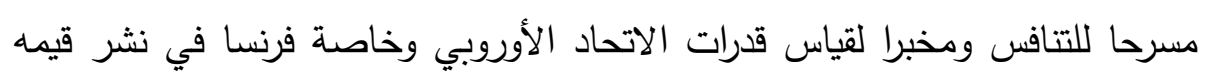
وتدبير الأزمات في دول الساحل. تبقى مساعي الاتحاد الأوروبي لتوظيف سياسته في الساحل الأفريقي رهينة مدى التوافق بين متطلبات تحقيق هذه السياسة وبين خصوصية المنطقة وتعدد المفارقات التي لتئي

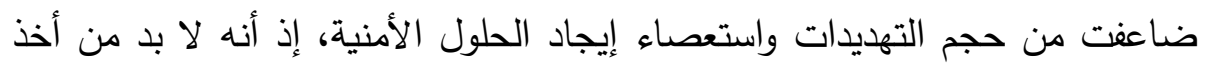

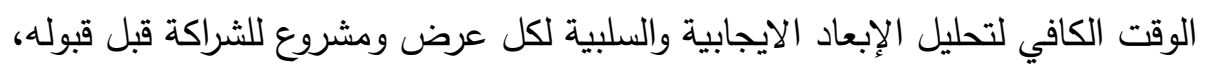

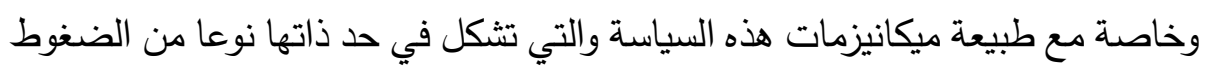

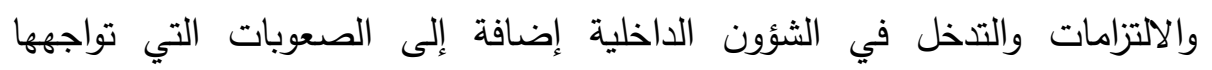
|قتصاديات دول المنطقة. - - نجاح بعض البرامج والمشاريع التتموية الأوروبية لم ولن يسهم في إحداث الموازنة بين

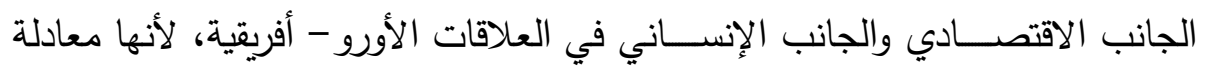

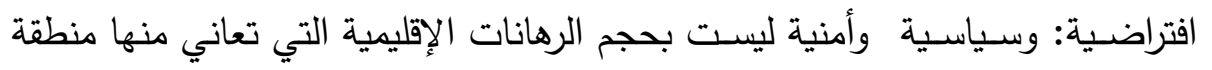

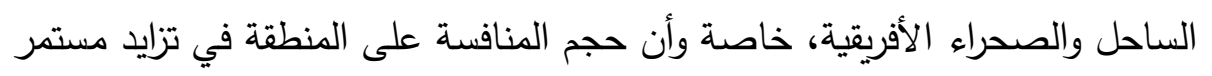

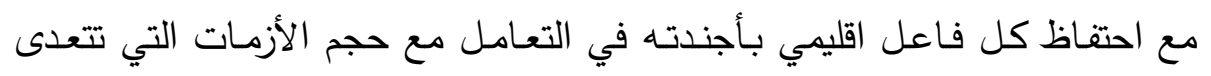

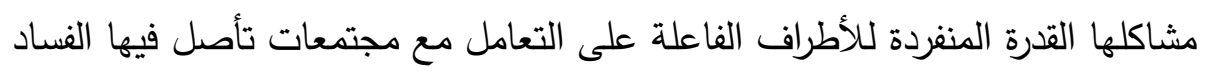

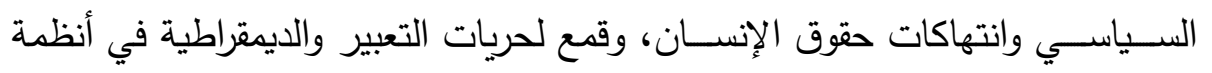
شمولية عززتها الفروقات القبلية والاثثية. - - لا تزال الشراكة الأوروبية الأفريقية تعكس انفراد بعض الدول الأوروبية بالحركة والفعل

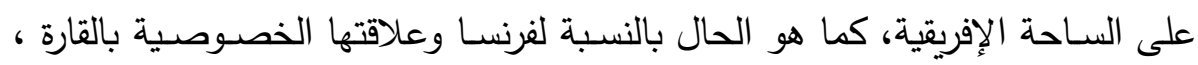

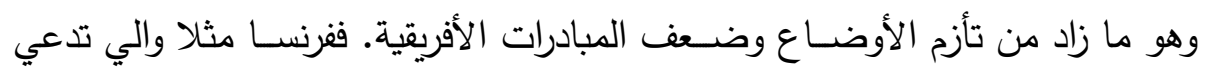
حسن مقاصدها في مساعدة المنطقة على الخروج من مشاكلها، هي نفسها التي تبيعها الأعداد الكبيرة من الأسلحة، ودعم الجماعات الارهابية.

- - طالما اعتبرت الدول الأوروبية نفســـها أَوْلى الأطراف الدولية الأخرى وأحقّها ارتباطاً

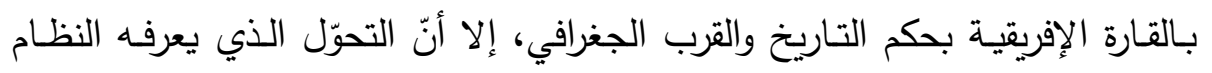

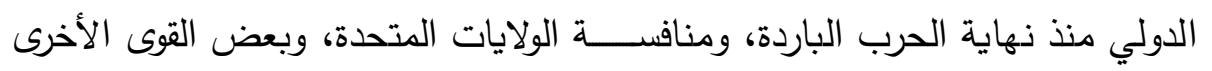

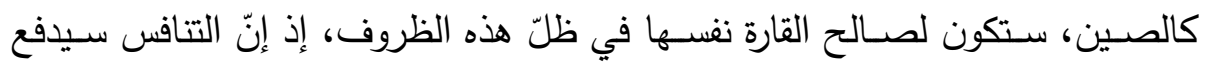




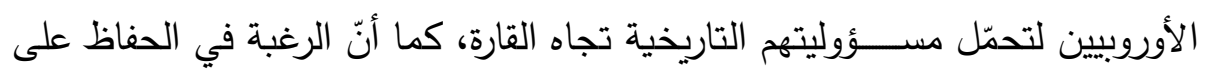
مصالحهم ستجعلهم أكثر حرصاً على العمل المشترك مع الأفارقة لأجلها.

- - من الضروري أن تعيد دول الساحل النظر في مصالحها بما يتماشى ومتطلبات الفرد

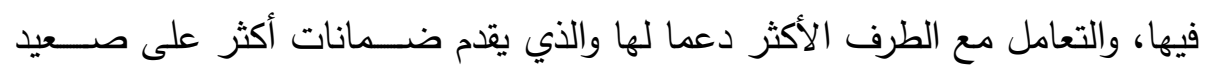

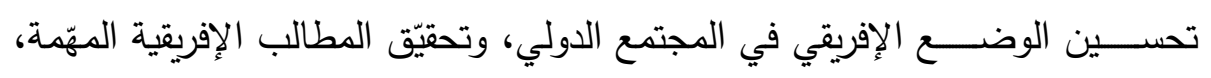

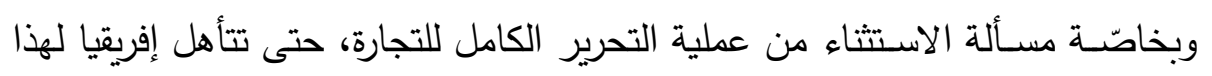
الوضح، وكنلك الإعفاء من الديون التي تكبّل الاقتصاديات الإفريقية.

- تقديم الاتحاد الأوروبي الحلول لتدبير الأزمات في المنطقة لا يفتأ يظل مجرد بدائل

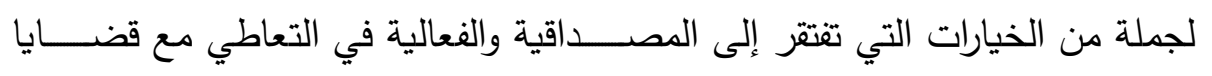

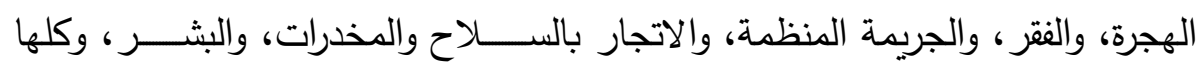

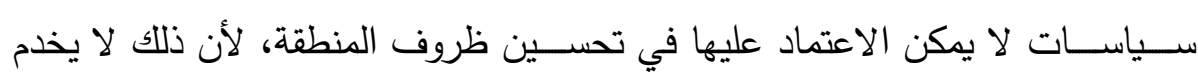

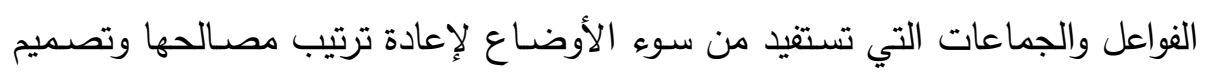
أهدافها في استغلال ثروات المنطقة.

- - يعتبر البعض أن مســاهمة الاتحاد الأوروبي تقتصـر على أدوات القوة الناعمة، لكن

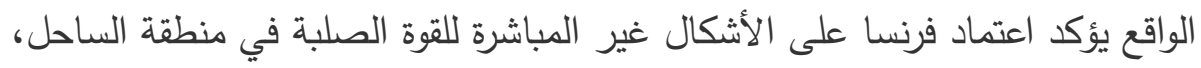

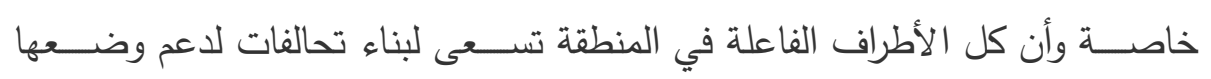
الاستراتيجي مع اشتداد التنافس على مصادر الطاقة وثروات المنطقة.

1“Sahel”, www.http:/newworldencyclopedia.org, Retrieved 2-6-2019.

2 صيفي مشاور، " "دور الجغرافيا السياسية في تكوين الدولة في منطقة الساحل الإفريقي"، الحوار الفكري، المجلد 11، العدد 12، ص-ص سن 210 210-230.

3 منصور لخضاري، الساحل الإفريقي وبناء الأمن الوطني الجزائري، إصدار مديرية الإعلام والاتصال والتوجيه، الجزائر المؤسسة الوطنية للاتصال والنشر والإثهار، 2012م.

4 التقرير الأوروبي حول التتمية لعام 2009، "التغلب على الهثاشة في افريقيا"، مركز رويرت شومان للدراسات المتقدمة المعهد الجامعي الأوروبي، سان دمينيكو دي فيسولي.

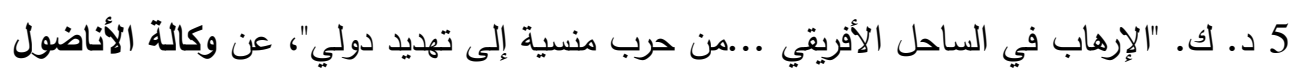

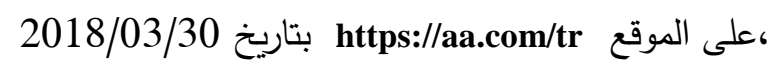




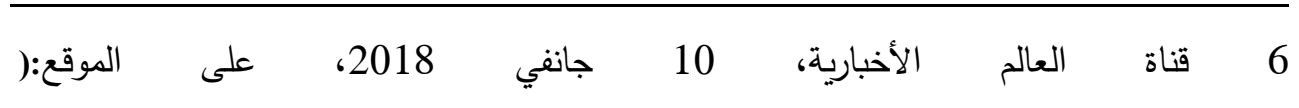

$$
\begin{aligned}
& \text { (https://www.alalamtv.net/news/3278841 } \\
& 7 \text { شريف سيد كامل، الجريمة المنظمة، القاهرة، دار النهضة العربية، الطبعة الأولى، 2001، ص } \\
& 8 \text { محمد بشير جوب،"سياسات الاتحاد الأوروبي تجاه الهجرة ... اتجاهاتها وانعكاساتها على المهاجرين }
\end{aligned}
$$

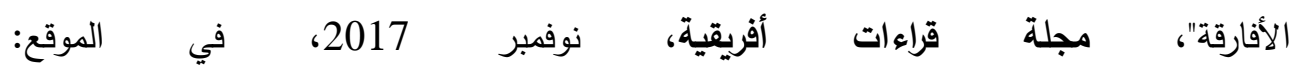

$$
\begin{aligned}
& \text { (https://www.qiraatafrican.com/home/new/) } \\
& 9 \text { صليحة كبابي، التحولات الأمنية في الاتحاد الأوروبي وإنعكاساتها على دول المغرب العربي، }
\end{aligned}
$$

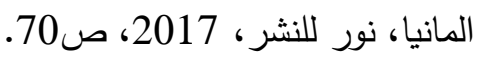

10BROOKS (Rosa Ehrenreich), "Failed States, or the State as Failure?", Georgetown Law Faculty Publications and Other, Works. Paper 1108, 2005, in (http://scholarship.law.georgetown.edu/facpub/1108).

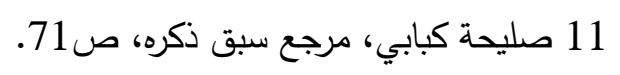

12 خديجة عرفة محمد أمين، الأمن الإنساني: المفهوم والتطبيق في الواقع العربي والدولي، الرياض،

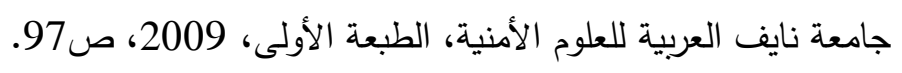$$
\text { 13نفس المرجع ، ص } 99
$$

14BULL (Hadley), "Civil Power Europe: a Contradiction in Terms?", in Journal of Common Market Studies, United States, vol 21(2),1982, p156.

15GUltung (Johan), The European Community: A Superpower in the Making, London, (Allen and Unwin Editions, 1973, p 33.

$$
16 \text { صليحة كبابي، مرجع سبق ذكره، ص154 } 153
$$

17الكسندر واندت، النظرية الاجتماعية للسياسة الدولية، ترجمة د.عبد الله جبر صالح العتيبي، الرياض،

$$
\begin{aligned}
& \text { جامعة الملك سعود، } 2006 \text { ص190. }
\end{aligned}
$$

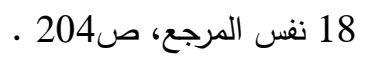

19 Claire Rodier, «Externalisation du contrôle des flux migratoires : comment et avec qui l'Europe repousse ses frontières », Dans Migrations Société 2008/2 ( N 116), pages 105 à 122.

$$
20 \text { صليحة كبابي مرجع سبق ذكره، ص } 159 .
$$

21 صدام مرير الجميلي ، الاتحاد الأوروبي ودوره في النظام العالمي الجديد، لبنان، دار المنهل

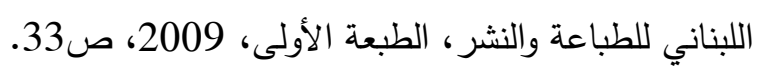

22 هشام صاغور ، السياسة الخارجية للاتحاد الأوروبي تجاه دول جنوب المتوسط، الإسكندرية،

$$
\text { مكتبة الوفاء القانونية، الطبعة الأولى، 2010، صنام السيلة } 255
$$


23 رواد غالب سليقة، إدارة الأزمات الدولية في ظل نضام الأمن الجماعي، منشورات الحلبي الحقوقية،

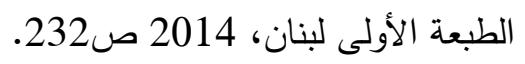

24 المفوضية الأوروبية، " تقرير مشترك موجه للبرلمان الأوروبي والمجلس الأوروبي واللجنة الاقتصادية والاجتماعية الأوروبية ولجنة المناطق: مراجعة السياسة الأوروبية للجوار ، بروكسل، 18 تثرين http://eeas.europa.eu/archives/docs/enp/documents/2015/151118_jointcommunication_revie

26 تقرير المفوضية الأوروبية، رجع سبق ذكره. 27نفس المرجع. 